\title{
Agroinoculation of Citrus tristeza virus Causes Systemic Infection and Symptoms in the Presumed Nonhost Nicotiana benthamiana
}

\author{
Silvia Ambrós, ${ }^{1}$ Choaa El-Mohtar, ${ }^{2}$ Susana Ruiz-Ruiz, ${ }^{1}$ Leandro Peña, ${ }^{1}$ José Guerri, ${ }^{1}$ William O. Dawson, ${ }^{2}$ \\ and Pedro Moreno'
}

${ }^{1}$ Centro de Protección Vegetal y Biotecnología, IVIA, Moncada, Valencia-46113, Spain; ${ }^{2}$ University of Florida, C.R.E.C., Lake Alfred, Florida-33850-2299, U.S.A.

Submitted 5 May 2011. Accepted 25 June 2011.

\begin{abstract}
Citrus tristeza virus (CTV) naturally infects only some citrus species and relatives and within these it only invades phloem tissues. Failure to agroinfect citrus plants and the lack of an experimental herbaceous host hindered development of a workable genetic system. A full-genome cDNA of CTV isolate T36 was cloned in binary plasmids and was used to agroinfiltrate Nicotiana benthamiana leaves, with or without coinfiltration with plasmids expressing different silencing-suppressor proteins. A time course analysis in agroinfiltrated leaves indicated that CTV accumulates and moves cell-to-cell for at least three weeks postinoculation (wpi), and then, it moves systemically and infects the upper leaves with symptom expression. Silencing suppressors expedited systemic infection and often increased infectivity. In systemically infected Nicotiana benthamiana plants, CTV invaded first the phloem, but after $7 \mathrm{wpi}$, it was also found in other tissues and reached a high viral titer in upper leaves, thus allowing efficient transmission to citrus by stem-slash inoculation. Infected citrus plants showed the symptoms, virion morphology, and phloem restriction characteristic of the wild T36 isolate. Therefore, agroinfiltration of Nicotiana benthamiana provided the first experimental herbaceous host for CTV and an easy and efficient genetic system for this closterovirus.
\end{abstract}

Citrus tristeza virus (CTV), a member of genus Closterovirus, family Closteroviridae, is the most destructive viral pathogen of citrus and one of the more economically important plant viruses. In nature, its host range is restricted to species of a few genera within the subfamily Aurantioideae, and within infected plants, the virus invades only phloem tissues. CTV has been experimentally transmitted to Passiflora gracilis and P. caerulea (Müller et al. 1974; Roistacher and Bar-Joseph 1987), two perennial vines, but attempts to transmit it to herbaceous and other nonrutaceous woody species, including Nicotiana benthamiana and other Nicotiana species, were unsuccessful (Müller and Garnsey 1984; our unpublished results). Almost 100 million trees propagated on sour orange rootstocks

Current address for Susana Ruiz-Ruiz: Instituto de Biología Molecular y Celular de Plantas, UPV-CSIC, Valencia-46022, Spain.

Corresponding author: Pedro Moreno; Telephone: +34 96342 4000; Fax: +34 96342 4001; E-mail: pmoreno@ivia.es

*The $\boldsymbol{e}$-Xtra logo stands for "electronic extra" and indicates that a supplementary figure is published online. died worldwide from tristeza epidemics, and presently, many millions more propagated on decline-tolerant rootstocks are debilitated by stem pitting-inducing CTV isolates (Bar-Joseph and Dawson 2008; Moreno and Garnsey 2010).

CTV virions $(2,000 \times 10$ to $12 \mathrm{~nm})$ are composed of a single-stranded, positive-sense genomic RNA (gRNA) of about $20 \mathrm{~kb}$ and two coat proteins of $25(\mathrm{CP})$ and $27(\mathrm{CPm}) \mathrm{kDa}$ that encapsidate about 97 and 3\% of the gRNA, respectively (BarJoseph and Lee 1989; Gowda et al. 2009; Satyanarayana et al. 2004). The CTV gRNA is organized into 12 open reading frames (ORF) and nontranslated regions (NTR) of 107 and $273 \mathrm{nt}$ at the $5^{\prime}$ and $3^{\prime}$ termini, respectively (Karasev et al. 1995). ORF 1a and 1b, encompassing the $5^{\prime}$ half of the genome, encode replicase-related proteins that are translated from the gRNA. The $349-\mathrm{kDa}$ protein encoded by ORF 1a contains two papainlike protease domains plus methyltransferaselike and helicaselike domains, and its translation is thought to occasionally continue through the polymeraselike domain encoded by ORF 1 b by a +1 frameshift. The ten $3^{\prime}-$ proximal ORF encode proteins p33, p6, p65, p61, p27, p25, p18, p13, p20, and p23, which are expressed via 3 ' coterminal subgenomic RNAs (sgRNAs) (Hilf et al. 1995), promoted by internal controller elements (Gowda et al. 2001). Proteins p65, p61, p27, and p25 are part of a group involved in virion assembly and movement that is conserved among closteroviruses (Dolja et al. 2006; Gowda et al. 2009; Satyanarayana et al. 2000, 2004; Tatineni et al. 2010). The function of p33, p18, and p13 is presently unknown, and deletion mutants lacking these genes are able to systemically infect some citrus species (Tatineni et al. 2008). Proteins p25, p20, and p23 have been shown to act as silencing suppressors in $N$. benthamiana and N. tabaccum plants (Lu et al. 2004).

Setting up a genetic system based on an infectious cDNA clone was a challenging objective because i) the large size of the CTV genome hindered preparation of full-length cDNA clones and, then, of intact RNA transcripts for inoculation; ii) although citrus can be mechanically inoculated by slashing citrus stems with CTV virions (Garnsey et al. 1977), all attempts to mechanically inoculate them with virion RNA or RNA transcripts from a cDNA clone were unsuccessful (Satyanarayana et al. 2001); and iii) we lacked an herbaceous host for experimentation. Satyanarayana and associates (1999) developed a full-length cDNA clone of the CTV isolate T36 (CTV-T36) genome, from which they synthesized in vitro RNA transcripts that infected $N$. benthamiana protoplasts and produced normal CTV virions. However, due to the large size and fragility of the RNA transcripts and the difficulty of inoculating proto- 
plasts with such large RNAs, the protoplast infection rate was low (about $10^{-4}$ ) and the amount of virions obtained was insufficient for successful infection of citrus plants by mechanical inoculation. This made necessary virion amplification by five to six cycles of protoplast inoculations to show that these virions systemically infected citrus plants and were able to incite symptoms identical to those of the wild T36 isolate (Satyanarayana et al. 2001). These limitations make this genetic system very tenuous. The transfer process often failed.

Viral genomes have been efficiently delivered into plant cells by infiltrating tissues with Agrobacterium tumefaciens cultures carrying appropriate binary plasmids with a full-length cDNA of the virus genome (Grimsley et al. 1986). This procedure has been successfully used with a citrus-infecting virus (Vives et al. 2008) and with several phloem-limited viruses (Leiser et al. 1992; Stephan and Maiss 2006), including members of the family Closteroviridae (Chiba et al. 2006; Liu et al. 2009; Wang et al. 2009). However, previous attempts to agroinoculate alemow (C. macrophylla Wester) or Mexican lime (C. aurantifolia (Christ.) Swing.) plants with binary plasmids carrying a cDNA clone of CTV-T36 were unsuccessful (Gowda et al. 2005; our unpublished data). Therefore, trials were aimed at developing a genetic system based on agroinfiltration of $N$. benthamiana plants as intermediate host to produce enough CTV virions to mechanically infect citrus plants by stem-slash inoculation. In preliminary experiments citrus plants were successfully infected with purified virion extracts from agroinfiltrated $N$. benthamiana leaves harvested at 7 to 8 days postinfiltration (dpi) (Gowda et al. 2005); however, erratic results in different experiments made the procedure unreliable. In this work, we agroinfiltrated $N$. benthamiana leaves with several binary plasmids carrying a cDNA of the CTV-T36 genome and different silencing suppressors and performed a timecourse analysis of CTV accumulation in those leaves. Unexpectedly, we found that agroinoculated plants of this species, presumed to be 'nonhost,' were systemically invaded by CTV-T36 with high viral titers both at the inoculated and upper leaves, in which typical disease symptoms were observed. The virus was eventually found also in nonphloem tissues, reaching an even higher viral load in the upper leaves. Citrus plants mechanically inoculated with virions produced in $N$. benthamiana were systemically infected, showed the symptoms characteristic of the wild CTV-T36 isolate, and kept the virus restricted to the phloem.

\section{RESULTS}

\section{Construction, stability, and in planta functionality} of binary plasmids expressing the CTV genome.

Previous attempts to infect citrus plants directly by biolistic or mechanical inoculation of full-genome cDNA clones of CTV-T36 were unsuccessful (Gowda et al. 2005; our unpublished data). Since this CTV genotype was known to replicate in $N$. benthamiana protoplasts, we tried to develop a workable genetic system based on agroinfiltration of these clones after subcloning them in appropriate binary plasmids. For this purpose, we constructed the pUC-based plasmid p35SC31 carrying a full-genome cDNA of CTV-T36 (clone pCTV9) followed by a ribozyme, located between the $35 \mathrm{~S}$ promoter of the Cauliflower mosaic virus (CaMV) and the nopaline synthase terminator (NOS-t) (Fig. 1C; Table 1). A minireplicon having the elements essential for replication (p35S $\Delta \mathrm{Cla} 9$ ) was also obtained from p35SC31, as described by Satyanarayana and associates (1999) (Fig. 1C and D; Table 1). These constructs were designed to obtain, in planta, a CTV gRNA or a minireplicon with the precise $5^{\prime}$ and $3^{\prime}$ termini after subcloning the expression cassette in a binary plasmid and using this for plant agroinfiltration.
A major problem with CTV cDNA clones is the presence in ORF 1a of sequences toxic for bacteria, which impair their normal growth and cause plasmid reorganizations, particularly when using high copy-number plasmids. Moreover, the first cDNA clone of CTV-T36 (pCTV9) that had an accidental frameshift mutation at position 3,732 (Fig. 1D) had these problems but a restored version thereof (pCTV9R) was even more toxic (Satyanarayana et al. 2003). We tried first to use pBIN19, a low-copy binary vector (10 to 20 copies per cell), but only the constructs derived from pCTV9 (pBINCTV9 and pBIN $\Delta$ Cla9) could be assembled. Agroinfiltration of $N$. benthamiana leaves with A. tumefaciens EHA105 or COR308 (Hamilton 1997) cultures transfected with these constructs resulted in a faint expression of the CTV minireplicon or the gRNA (data not shown) at 5 days postinfiltration (dpi) only when coinfiltrated with a silencing suppressor (Fig. 2A). Expression of CTV gRNA decayed quickly and did not give a stable infection (data not shown).

To improve the stability of CTV cDNA clones we i) inserted a plant intron to interrupt the toxic sequence in the CTV genome and ii) used a bacterial artificial chromosome (BAC) that produces one to two copies per cell and is capable of maintaining large eukaryotic cDNA fragments (Hamilton 1997). The intron 2 of the $S T-L S-1$ gene of potato was inserted at positions 3,652 or 3,744 in ORF 1a of the minireplicon $\mathrm{p} 35 \mathrm{~S} \Delta \mathrm{Cla} 295 \mathrm{R}$, a restored version of $\mathrm{p} 35 \mathrm{~S} \Delta \mathrm{Cla} 9$ without the frameshift mutation (Fig. 1D; Table 1), following a strategy that conserves the optimal consensus sequence for splicing in plants (Johansen 1996; Vancanneyt et al. 1990). Clones carrying the intron at either position (p35S $\Delta$ Cla295Rint) showed similar stability in Escherichia coli JM109 grown in Luria Bertani (LB) agarampicillin, that formed colonies of 1.1 to $1.3 \mathrm{~mm}$ in diameter 1 day after plating, in contrast to the 0.7 to $1.4 \mathrm{~mm}$ in diameter of the colonies produced by the parent clone without intron (p35S $\Delta$ Cla295R) after 2 days of incubation. The toxicity problem was eliminated and stabilization was observed in the fullgenome cDNA clone after intron insertion (p35SC31Rint) (Fig. 1D; Table 1), resulting in 1.2- to $1.4-\mathrm{mm}$ colonies 1 day after plating, compared with the 2 to 3 days required to obtain a similar size with the parent clone (Satyanarana et al. 2003). Subcloning of the minireplicon p35S $\Delta$ Cla295R or the fullgenome clones p35SC31 and p35SC31Rint into a BAC yielded BBAC $\Delta$ Cla295R, BBAC31, and BBAC31Rint plasmids, respectively (Fig. 1E; Table 1). BBAC31R was obtained by ligation of the $3^{\prime}$ terminal SmaI/NotI fragment of p35SC31 into BBAC $\Delta$ Cla295R (Fig. 1; Table 1). All of them were stable in E. coli $\mathrm{DH} 10 \mathrm{~B}$ grown on LB agar-kanamycin and formed visible colonies after 1 day, with BBAC31Rint producing larger 1day colonies (1.5 to $1.8 \mathrm{~mm}$ ) than BBAC31R (0.7 to $1.0 \mathrm{~mm}$ ).

The functionality of the new constructs in planta in comparison with others based on the high copy-number plasmid pCAMBIA1380 (50 to 100 copies per cell) was tested by agroinfiltrating $N$. benthamiana leaves with $A$. tumefaciens COR308 cultures transfected with plasmids BBAC $\Delta$ Cla295R or pCAM $\Delta$ Cla14R that carried a minireplicon of CTV-T36 (Table 1; Fig. 1), with or without expression of a silencing suppressor (Voinnet et al. 2003). Results with the two plasmids were similar; replication of viral RNA in agroinfiltrated leaves was detected by Northern blot at $5 \mathrm{dpi}$ and by reverse transcriptionpolymerase chain reaction (RT-PCR) at 3 and $5 \mathrm{dpi}$, with an apparent RNA increase at the latter sampling time (Fig. 2A and C). Expression of a silencing suppressor increased CTV RNA accumulation in both cases (Fig. 2A). Similar experiments delivering, in planta, the full-genome plasmids BBAC31 and BBAC31Rint showed that they were also functional and allowed transient expression of CTV gRNA in agroinfiltrated leaves, albeit plasmid with an intron (BBAC31Rint) showed higher 
viral RNA accumulation (Fig. 2B). The correct RNA splicing was verified by RT-PCR analysis of the viral progeny from BBAC31Rint using primers encompassing the intron region in the CTV cDNA. While PCR amplification from plasmids BBAC31Rint and BBAC31 yielded fragments of 622 and 433 bp, respectively, RT-PCR amplification using double-stranded
(ds)RNA from CTV-infected citrus or total RNA extracts (RNAt) from $N$. benthamiana leaves agroinfiltrated with BBAC31Rint yielded a unique fragment of 433 bp (Fig. 2B), indicating efficient removal of the 189-nt intron. Sequencing of the 433-nt fragment amplified from $N$. benthamiana confirmed that the original viral sequence had been restored.

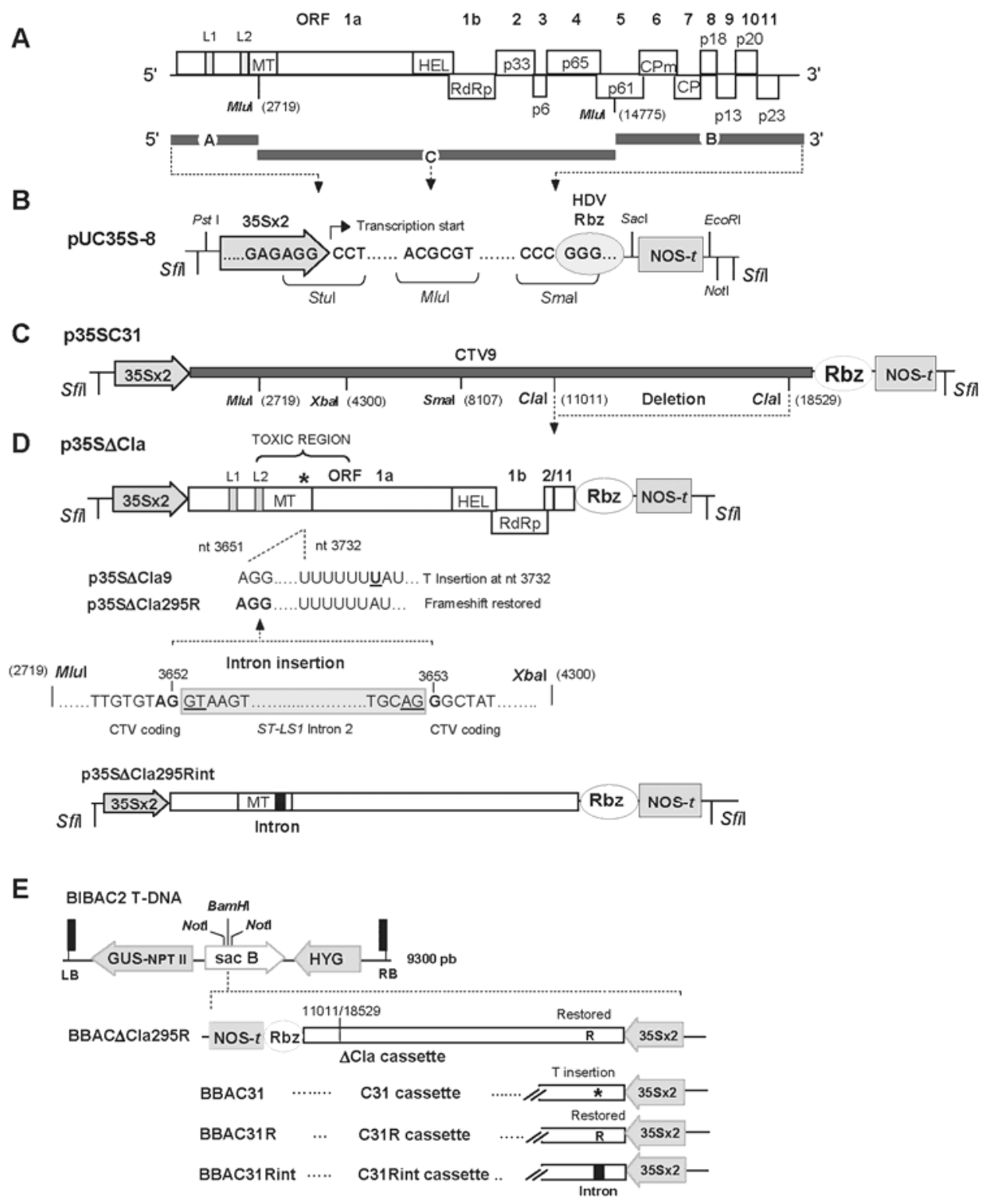

Fig. 1. Outline of the constructs used in this study. A, Genome organization of the Citrus tristeza virus (CTV) genomic (g)RNA. The boxes indicate open reading frames (ORF) and their corresponding translation products. L1 and L2 mean the two leader papainlike proteases; MT, methyltransferase; HEL, helicase; RdRp, RNA-dependent RNA polymerase; and CPm and CP, the minor and major coat proteins. Restriction sites used for subcloning and their position in the gRNA are indicated below. DNA products obtained by polymerase chain reaction amplification are shown below the genome map. B, Partial map of the pUC35S-8 vector containing a double-enhanced $35 \mathrm{~S}$ promoter $(35 \mathrm{~S} \times 2)$ of the Cauliflower mosaic virus $(\mathrm{CaMV})$, the Hepatitis delta virus ribozyme $(\mathrm{Rbz})$ and the nopaline synthase terminator (NOS-t). Relevant sequences for transcription start at the junction of the promoter and the viral sequence, for a precise $3^{\prime}$ end at the junction with the ribozyme, and restriction sites used for the subcloning steps are indicated. Dotted arrow lines indicate the cloning strategy to assemble the three cDNA segments encompassing the full CTV genome into the pUC35S-8 vector, using the MluI, StuI, and SmaI restriction sites. C, Map of the construct p35SC31, comprising the full-genome cDNA clone CTV9 in the pUC35S-8 vector. Relevant ClaI sites to prepare $\Delta$ Cla minireplicons and the external SfiI sites to release the complete expression cassette are indicated. D, Schematic representation of the p35S $\Delta$ Cla9 minireplicon prepared from the full-length p35SC31 construct by a large deletion. The asterisk indicates a region with a T insertion in the construct p35S $\Delta \mathrm{Cla} 9$ (nucleotide position 3,732 ) that was restored in the p35S $\Delta \mathrm{Cla} 295 \mathrm{R}$ clone (below). The AGG triplet was used to insert intron 2 of the ST-LS1 gene shown below. The strategy and

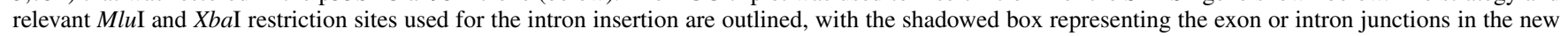
p35S $\Delta$ Cla295Rint viral construct (below), according to the intron sequence modified by Vancanneyt and associates (1990). Optimal consensus sequences for splicing in plants at the left and right borders are in bold (exon) or underlined (intron) characters. E, Detail of the T-DNA region in the BIBAC2 binary vector. RB and LB are the right and left borders. The NotI sites used for subcloning and the unique BamHI site present in the sacB gene are indicated. The $\beta$ glucuronidase-neomycin phosphotransferase II and the hygromycin phosphotransferase cassettes are selectable markers encoding a $\beta$-glucuronidase-neomycin phosphotransferase II fusion peptide and hygromycin resistance, respectively. The organization and relative orientation of the minireplicon or full-length CTV cDNA in the T-DNA of the BIBAC-based constructs is shown below. 
We then examined the kinetics of CTV accumulation by analyzing $N$. benthamiana leaves agroinfiltrated with plasmids BBAC31R and BBAC31Rint at 3, 6, 12, 18, and 21 dpi by enzyme-linked immunosorbent assay (ELISA), Northern blot, and real-time quantitative (q)RT-PCR. Northern blot analysis showed that accumulation of CTV gRNA and sgRNAs increased for at least 3 weeks postinfiltration (wpi) (Fig. 2D). ELISA readings also confirmed CTV increase, with positive detection beginning at 8 to $12 \mathrm{dpi}$. CTV gRNA quantification by qRT-PCR showed that, in the presence of a silencing suppressor, i) the efficiency of both plasmids was similar and ii) the viral titer increased 15 to 30 times between 1 and 3 wpi (data not shown). These results suggest the potential of BAC plasmids to efficiently establish a CTV infection in agroinfiltrated $N$. benthamiana leaves for at least three weeks, albeit viral titer at that time may differ between experiments (e.g., in six different agroinfiltration experiments with BBAC31Rint, the average number of CTV gRNA molecules per nanogram of RNAt in agroinfiltrated leaves estimated at 21 dpi ranged from $2.1 \times 10^{2} \pm 3.7 \times 10^{1}$ to $1.1 \times 10^{4} \pm 3.2 \times 10^{3}$ ).

Virion extracts semipurified from agroinfiltrated $N$. benthamiana leaves at 3 wpi were mechanically inoculated onto alemow seedlings. Infectivity obtained with BBAC31R and BBAC31Rint plasmids in three different experiments, as detected by ELISA, was similar $(2: 8,0: 4$, and $0: 4$ vs. $3: 9,0: 4$ and 0:4 infected/inoculated citrus plants, respectively), and in all cases, the infected plants showed the symptoms characteristic of CTV-T36. CTV quantification by qRT-PCR showed that failure of mechanical transmission was usually associated with a low virus titer in agroinfiltrated $N$. benthamiana leaves (e.g., the mean virus load in $N$. benthamiana leaves agroinfiltrated with BBAC31R at harvesting time was $5.68 \times 10^{3} \pm 2.4 \times 10^{1}$ gRNA molecules per nanogram of RNAt for the first experiment and $2.1 \times 10^{2} \pm 3.7 \times 10^{1}$ for the second), and it was estimated that the threshold titer for successful citrus infection was around $5 \times 10^{3}$ to $10 \times 10^{3}$ gRNA copies per nanogram of RNAt, about two- to fivefold the CTV titer in infected alemow leaves.

\section{Effect of silencing suppressors on CTV agroinfection.}

Our preliminary data showed that CTV accumulation in agroinfiltrated $N$. benthamiana leaves was low, suggesting a reduced number of infection events. In an attempt to improve efficiency of agroinfection, we first compared the effect of p19 and p24, two potent silencing suppressors (Voinnet et al. 2003) encoded by Tomato bushy stunt virus and Grapevine leafrollassociated virus-2 (GLRaV-2), respectively, by delivering the pCAM9R-GFP (green fluorescent protein) vector (Table 1) that comprises a version of the pCTV9R infectious clone expressing GFP (Folimonov et al. 2007; Tatineni et al. 2008; unpublished data) to $N$. benthamiana leaves, with or without a suppressor-expressing plasmid. Transient expression of pCAM9R-GFP alone resulted in a reduced number of fluorescent foci at $10 \mathrm{dpi}$ that slightly increased in size at $21 \mathrm{dpi}$ (Fig. 3A), suggesting inefficient CTV infection and accumulation, probably due to a plant RNA-mediated antiviral response. In contrast, the number of fluorescent foci at 10 dpi was much higher when p19 or p24 was coexpressed with the CTV vector (Fig. 3A). The highest number and size of fluorescent foci was observed at 21 dpi in leaves coinfiltrated with the p24-expressing plasmid, albeit this suppressor induced yellowing and early senescence of the infiltrated leaves.

To confirm that GFP expression was due to CTV-GFP replication, we examined the kinetics of CTV gRNA accumulation in leaves agroinfiltrated with BBAC31Rint or pCAM9R-GFP plasmids, with or without p19 or p24, along a 4-wpi time course. Coexpression of CTV with a silencing suppressor increased CTV accumulation by two- to three- (p19) or 20- to 35 -fold (p24), in comparison with the cognate agroinfiltration without suppressor, as estimated by qRT-PCR (Fig. 3B) and confirmed by ELISA and Northern blot analyses (not shown). The CTV titer in leaves coinfiltrated with the pCAM9R-GFP vector was about twice that of the cognate leaves agroinfiltrated with BBAC31Rint, though the number of plasmid copies produced by pCAMBIA in bacterial cells is usually 50- to 100 -fold that of the BIBAC. Coinfiltration of BBAC31Rint or pCAM9R-GFP plasmids with silencing suppressors HC-Pro (helper component proteinase) from Tobacco etch virus or $\mathrm{p} 23$ from CTV also enhanced CTV accumulation in agroinfiltrated leaves compared with the no-suppressor control, with HC-Pro and p19 inducing a similar increase in CTV titers and p23 somewhat less (not shown).

\section{Agroinfiltration of CTV-T36 causes systemic infection of $N$. benthamiana.}

The agroinoculation in infiltrated leaf areas allows infection of cells from the nucleus and does not require cell-to-cell movement, as in the normal infection process. However, our

Table 1. Citrus tristeza virus (CTV) constructs used in this study

\begin{tabular}{|c|c|}
\hline Construct & Description \\
\hline pCTV9 & $\begin{array}{l}\text { Parent pUC plasmid with full-length cDNA of the CTV-T36 genome. This clone has a frameshift at nucleotide } 3,732 \\
\text { (Satyanarayana et al. 1999) }\end{array}$ \\
\hline pCTV9R & Parent plasmid with the frameshift restored (Satyanarayana et al. 2003) \\
\hline p35SC31 & Parent CTV9 clone assembled into pUC35S-8 vector \\
\hline p35S $\Delta \mathrm{Cla} 9$ & $\begin{array}{l}\text { Minireplicon obtained by a large internal ClaI deletion in p35SC31 (Satyanarayana et al. 1999). It expresses a hybrid p23 } \\
\text { subgenomic (sg)RNA }\end{array}$ \\
\hline $\mathrm{p} 35 \mathrm{~S} \Delta \mathrm{Cla} 295 \mathrm{R}$ & $\mathrm{p} 35 \mathrm{~S} \Delta \mathrm{Cla} 9$ minireplicon with the frameshift at position 3,732 restored \\
\hline p35S $\Delta$ Cla295Rint & p35S $\Delta$ Cla295R minireplicon with the $S T-L S 1$ intron 2 sequence inserted at nucleotide position 3,652 \\
\hline p35SC31Rint & p35SC31 with the frameshift restored and the $S T$ - $L S 1$ intron 2 sequence inserted at position 3,652 \\
\hline pBIN19-SfiI L3.7 & pBIN19-sGFP binary vector (Chiu et al. 1996) with a SfiI site added in the polylinker \\
\hline pBINCTV9 & pBIN19-SfiI L3.7 with the expression cassette of p35SC31 subcloned in SfiI \\
\hline pBIN $\Delta$ Cla9 & pBIN19-SfiI L3.7 with the expression cassette of p35S $\Delta$ Cla9 subcloned in SfiI \\
\hline pCAM9R & pCAMBIA1380 binary vector carrying an expression cassette of the CTV9R cDNA clone (Gowda et al. 2005) \\
\hline pCAM9R-GFP & $\begin{array}{l}\text { pCAM9R vector with the } g f p \text { gene (C3 version) inserted between the coat protein }(\mathrm{CP}) \text { and the CPm open reading frames } \\
\text { (Folimonov et al. 2007; Tatineni et al. 2008) }\end{array}$ \\
\hline pCAM $\Delta$ Cla14R & $\begin{array}{l}\text { pCAMBIA1380 carrying the expression cassette of a minireplicon similar to p35S } \Delta \text { Cla295R (Gowda et al. 2005). It expresses the } \\
\text { p23 sgRNA }\end{array}$ \\
\hline BBAC31 & BIBAC2 binary vector carrying the expression cassette of p35SC31 \\
\hline BBAC31R & Similar to BBAC31 but with the frameshift mutation of p35SC31 restored \\
\hline BBAC $\Delta$ Cla295R & BIBAC2 carrying the expression cassette of p35S $\Delta$ Cla295R \\
\hline BBAC31Rint & BIBAC2 carrying the expression cassette of p35SC31Rint \\
\hline
\end{tabular}


time-course analyses of CTV accumulation in agroinfiltrated leaves over 4 wpi showed an increase in the number and size of fluorescent foci and in the amount of viral RNA and coat protein that suggested infection of new cells by cell-to-cell movement. Moreover, unexpectedly, we observed that, after this period, CTV-T36 was able to systemically infect upper leaves and induce symptoms in $N$. benthamiana plants, previously considered a nonhost species. Specific symptoms consisted of stunting, epinasty, and crumpled new leaves, vein clearing, and necrosis of medium and upper leaves, and plant collapse and death after 2 to 4 mpi (Fig. 4).

CTV infection in upper leaves was confirmed by ELISA, Northern blot, qRT-PCR, and fluorescence (when using a CTVGFP vector). Repeated agroinfiltration assays using BAC- or pCAMBIA-based plasmids carrying the CTV9R sequence showed high rates of systemic infection even when no silencing suppressor was coinfiltrated with the CTV clone (Table 2), whereas no systemic infection was achieved with binary plasmids carrying the CTV9 sequence. Coexpression of a silencing suppressor was not essential for systemic infection, but it generally expedited long-distance movement and often improved infectivity, as previously observed in the agroinfiltrated leaves (Table 2A). In a first set of experiments infiltrating leaves with A. tumefaciens COR308, the earliest and most efficient systemic infection as detected by ELISA was achieved with p19 (73 to $93 \%$ average infected plants at $1 \mathrm{mpi}$ and 83 to $100 \%$ later), followed by p23 (56 to $77 \%$ infected plants at $1 \mathrm{mpi}$ and 78 to $85 \%$ later), and HC-Pro (56\% infected plants at $1 \mathrm{mpi}$ and $78 \%$ later), whereas no positive effect was observed with p24, even if it induced a fast accumulation of viral RNA in agroinfiltrated leaves (Table 2A). Early yellowing and necrosis of leaves agroinfiltrated with p24 likely jeopardized virus exit from these leaves, delaying long-distance movement and often reducing efficiency of systemic infection. In a second set of experiments agroinfiltrating a CTV-GFP clone with A. tumefaciens EHA105, the most efficient systemic infection $(97 \%$ average infected plants), as detected by discontinuous fluorescence in upper leaf veins at $3 \mathrm{wpi}$, was obtained using a mix of the silencing suppressors p22 of Tomato chlorosis virus (ToCV) (Cañizares et al. 2008), p19, p24, and HC-Pro of Turnip mosaic virus, followed by individual expression of HC-Pro $(69 \%)$ or p22 $(59 \%)$ (Table 2B). A major improvement in the efficiency of systemic infection was obtained by subcloning the $\mathrm{p} 22$ silencing suppressor in the pCAMBIA vector carrying the CTV infectious clone, so that both acted always in cis. Agroinfiltration of leaves or injection into stems of $N$. benthamiana plants using this double vector yielded $100 \%$ systemic infection that was detected as early as 10 to $18 \mathrm{dpi}$ (more than 50 plants inoculated).
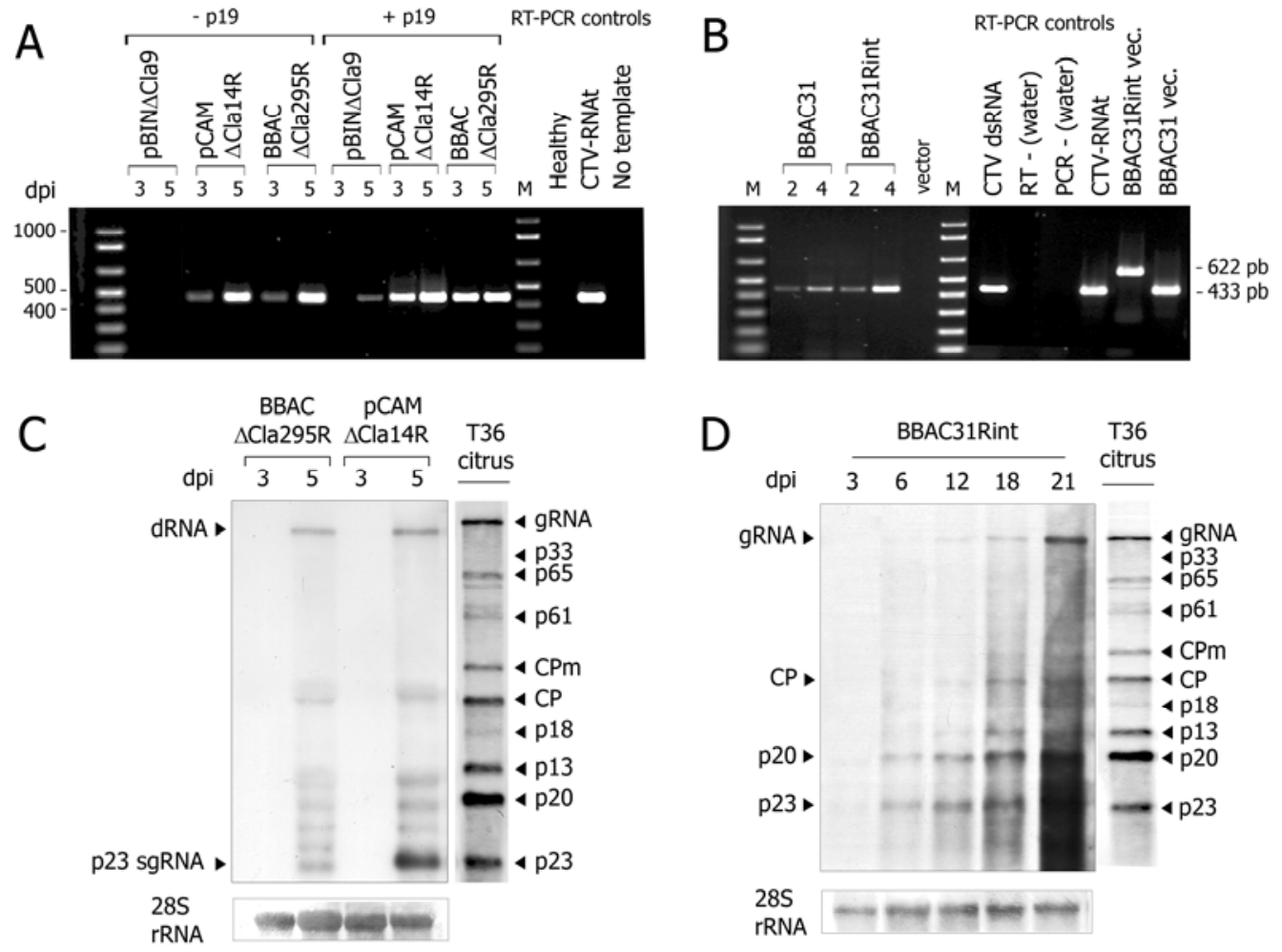

Fig. 2. Replication of the Citrus tristeza virus (CTV) full genome or minireplicons thereof in Nicotiana benthamiana leaves agroinfiltrated with binary plasmids carrying the cognate cDNA. A, Detection of the CTV $\Delta$ Cla minireplicon after agroinfiltration with plasmids pBIN $\Delta \mathrm{Cla} 9$, pCAM $\Delta \mathrm{Cla} 14 \mathrm{R}$, or BBAC $\Delta$ Cla295R with (+) or without (-) the p19 silencing suppressor. Reverse transcription-polymerase chain reaction (RT-PCR) amplification products obtained with primers PM118-PM119 and total RNA extracts (RNAt) from the agroinfiltrated areas at 3 and 5 days postinfiltration (dpi). Control: products amplified from healthy and CTV-infected citrus plant extracts or from distilled water. M, 1 Kb Plus DNA marker (Invitrogen Life Technologies, Carlsbad, CA, U.S.A.), with relevant sizes of DNA fragments indicated at the left. B, Confirmation of intron splicing in RNA progeny derived from the construct BBAC31Rint. RT-PCR amplification products obtained from $N$. benthamiana leaves agroinfiltrated with BBAC31, BBAC31Rint, or empty BIBAC vector at 2 or 4 dpi as in A. Control: PCR amplification products from BBAC31 or BBAC31Rint plasmids and RT-PCR products obtained from CTV-infected citrus plant extracts (RNAt or dsRNA) or from distilled water. Numbers at the right indicate the size of DNA fragments amplified from the intron-containing cDNA (622 bp) and its intronless counterpart (433 bp). C, Northern blot analysis of RNAt (4 $\mu \mathrm{g}$ ) from $N$. benthamiana leaves coinfiltrated with Agrobacterium tumefaciens COR308 transfected with plasmids BBAC $\Delta$ Cla295R or pCAM $\Delta$ Cla14R and a vector expressing the p19 silencing suppressor at 3 or 5 dpi. The right lane shows the positions of the genomic (g)RNA and subgenomic (sg)RNAs produced by CTV-T36 in an infected citrus plant, and arrowheads in the left indicate positions of the defective RNA of the minireplicon (dRNA) and p23 subgenomic (sg)RNA. The blot was hybridized with a digoxigenin-labeled riboprobe specific for the CTV $3^{\prime}$ nontranslated region. Methylene blue staining of the membrane shows the 28S rRNA used as loading control. D, Northern blot analysis of RNAt $(3 \mu \mathrm{g})$ from $N$. benthamiana leaves coinfiltrated with BBAC31Rint and p19 plasmids at 3, 6, 12, 18, and 21 dpi. The right lane shows the positions of the CTV-T36 gRNA and sgRNAs as in C. Hybridization and loading control also as in C. 
Systemic infection resulted in high CTV accumulation in new leaves in a short period of time, generally 1 to $2 \mathrm{mpi}$ (Fig. 5A). Indeed comparison of the viral titer in upper $N$. benthamiana and in citrus leaves by qRT-PCR showed that CTV accumulation was about 10- to 25-fold higher in the first than in the second host. Viral accumulation in new leaves of $N$. benthamiana was similar in plants agroinfiltrated with BBAC or with pCAMBIA plasmids, and coinfiltration with p19 often resulted in at least 1.5- to twofold increase in viral titer in comparison with plants agroinfiltrated without suppressor or coinfiltrated with p24 (Fig. 5A and B). The presence of CTV in nonagroinfiltrated new leaves could be due to systemic movement of A. tumefaciens (Cubero et al. 2006) followed by transient expression of CTV gRNA rather than to autonomous long-distance movement of CTV virions from agroinfiltrated leaves. We tested for the presence of A. tumefaciens in agroinfiltrated leaves at different times postinfiltration and in systemically infected new leaves by PCR with primers directed to the chromosomic gene $c h v \mathrm{E}$ and found that i) bacterial DNA was detected in most agroinfiltrated leaf samples until $1 \mathrm{mpi}$, with occasional detection being achieved between 1 and 1.5 mpi, but no detection after this time, and ii) bacterial DNA amplification was not achieved along a time course of $2 \mathrm{mpi}$ in upper leaves or even in noninfiltrated areas of the agroinfiltrated leaves showing CTV infection as detected by GFP fluorescence or by ELISA or qRT-PCR analyses, singly or together.

A

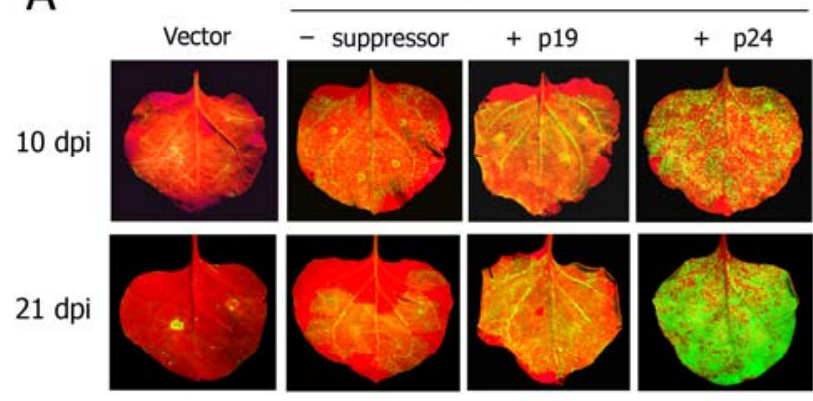

B

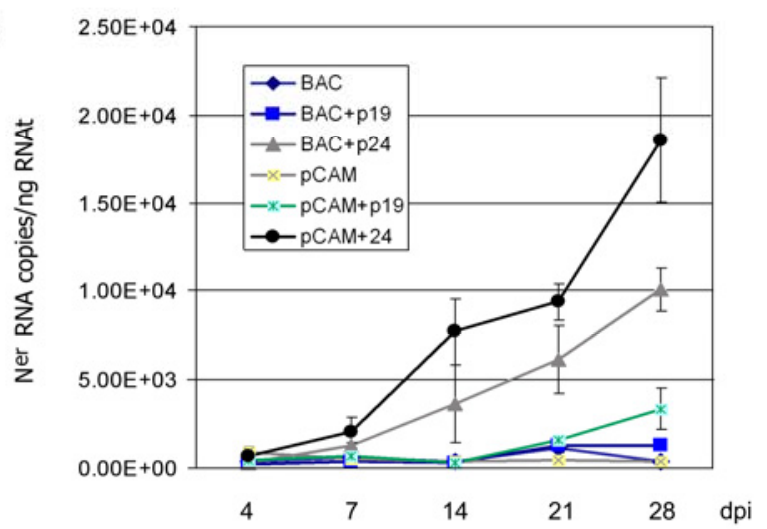

Fig. 3. Effect of silencing suppressors on Citrus tristeza virus (CTV) accumulation in agroinfiltrated Nicotiana benthamiana leaves. A, Fluorescence in $N$. benthamiana leaves infiltrated with Agrobacterium tumefaciens COR308 harboring an empty vector or the construct pCAM9R-GFP alone or in combination with others expressing p19 or p24 silencing suppressors. Photographs taken at 10 or 21 days postinoculation (dpi), illuminating the plants with a $100 \mathrm{~W}$ UV hand lamp. B, CTV accumulation in N. benthamiana leaves agroinfiltrated with constructs BBAC31Rint or pCAM9RGFP with or without silencing suppressors p19 or p24. Number of CTV genomic RNA copies per ng of total RNA extracts (RNAt) measured by quantitative reverse transcription-polymerase chain reaction (Ruiz-Ruiz et al. 2007) at 4, 7, 14, 21, and 28 dpi. Means and standard deviations were obtained from four technical replicates in two independent bioassays.
These results do not support involvement of A. tumefaciens in the CTV long-distance movement observed in N. benthamiana.

\section{Distribution of CTV-T36 is phloem-restricted in citrus but not in $N$. benthamiana.}

Monitoring CTV distribution in systemically infected $N$. benthamiana plants by tissue-print ELISA or by fluorescence emitted by CTV-GFP showed that the presence of the virus in new leaves, stems, young shoots, or roots was always associated with symptom expression (Fig. 4IIA and IIB). Plants coinfiltrated with CTV-GFP and silencing suppressors in trans initially ( 3 to 5 wpi) showed uneven virus distribution limited to the main veins or veinlets of some medium or upper leaves. Small fluorescent spots were observed during this period and the viral titer was still relatively low (Fig. 4IIC). After 1 to 2 additional weeks, the virus invaded new leaves and stems more efficiently and accumulated at higher levels, albeit it still remained phloem-limited, as revealed by tissue prints or by fluorescence observed in leaf petioles, young shoots, roots, stems, or leaves (Fig. 4ID1 and 2 and IID). At this stage CTV distribution resembled that observed in natural infections of citrus hosts (Fig. 4ID3). However, at 7 to 8 wpi, the virus was readily detected in other tissues, leading to a high viral titer (Fig. 4IE, IIE, and IIF). Systemic spread was expedited using in cis CTV gRNA and p22 chimeric constructs.

Virions from systemically infected $N$. benthamiana leaves (CTV-NB) observed by electron microscopy were similar to those from infected citrus tissues (Fig. 4IC). Purified virion preparations from these new leaves were infectious on alemow plants upon mechanical inoculation (Table 3), and reproduced the symptoms characteristic of the wild CTV-T36 (leaf cupping, vein clearing, and stunting). The ratio of infected plants obtained by inoculation with CTV-NB preparations from systemically infected $N$. benthamiana plants agroinfiltrated with BAC- or pCAMBIA-based plasmids were similar and usually averaged between 73 and $87 \%$. Moreover, the high viral titer of systemically infected $N$. benthamiana leaves enabled us to infect citrus using crude sap extracts, albeit transmission with this inoculum source was less efficient and symptom onset was delayed (29 to $33 \%$ average infected citrus plants at $2 \mathrm{mpi}$ ) (Table 3). Distribution of CTV or CTV-GFP in citrus slashinoculated with CTV-NB virions was restricted to the phloem of young shoots, leaf veins or petioles, stem bark or roots, as in naturally infected citrus, and the virion morphology observed at the electron microscope was also normal (Supplementary Fig. 1). These results confirm that CTV passage through $N$. benthamiana, in which the virus is not phloem-limited, does not change its original biological characteristics.

Summarizing, agroinfection of the presumed nonhost species $N$. benthamiana using BAC- or pCAMBIA-based plasmids to incite a systemic infection provides a novel genetic system for CTV that is simpler, faster, and more efficient than the available protoplast-based system (Satyanarayana et al. 1999, 2001).

\section{DISCUSSION}

Previous efforts to agroinfect citrus with CTV using binary plasmids and different silencing suppressors, oncogenic or disarmed A. tumefaciens strains, and agroinfiltration conditions were unsuccessful (our unpublished data). CTV could not be detected in agroinfiltrated tissues by ELISA, conventional RTPCR, or fluorescence (when using CTV-GFP). Occasionally, a faint amplification was detected by qRT-PCR that later disappeared, suggesting a subliminal infection that did not progress. For this reason, and because CTV-T36 was known to replicate in $N$. benthamiana protoplasts (Navas-Castillo et al. 1997; Satyanarayana et al. 1999), we tried to develop a genetic sys- 


\section{BBAC31Rint}

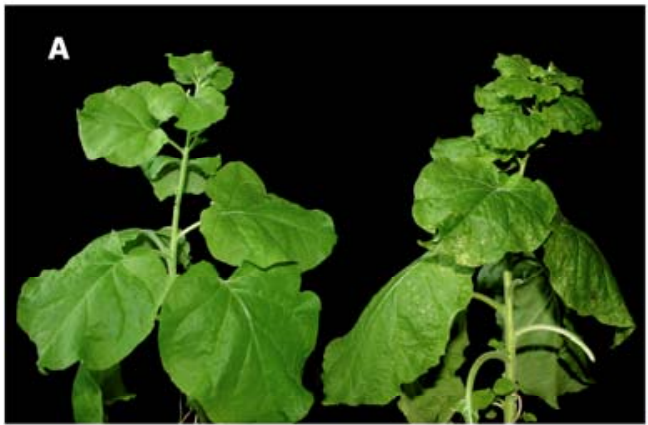

D

Phloem restricted

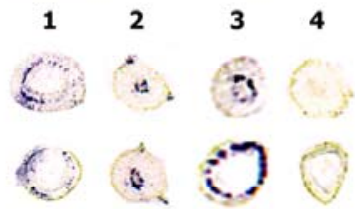

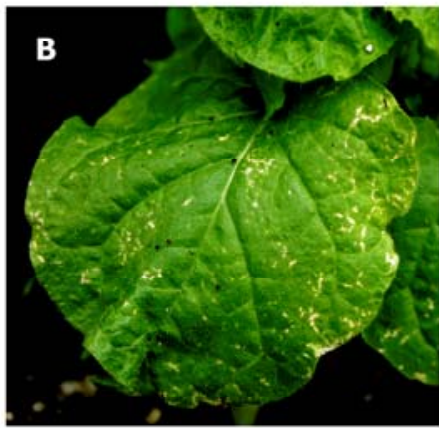

\section{E}

Invasion of non-phloem tissues

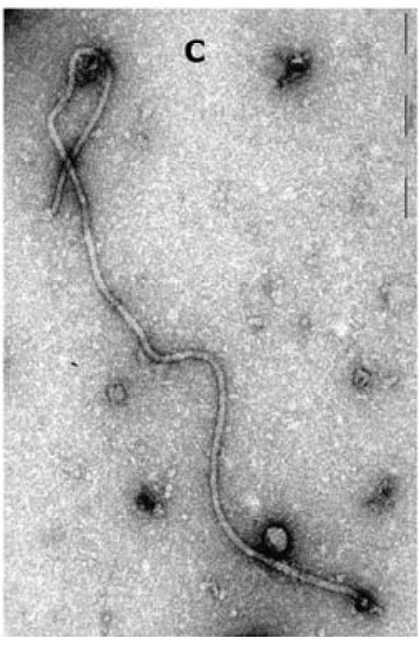

\section{II pCAM9R-GFP}
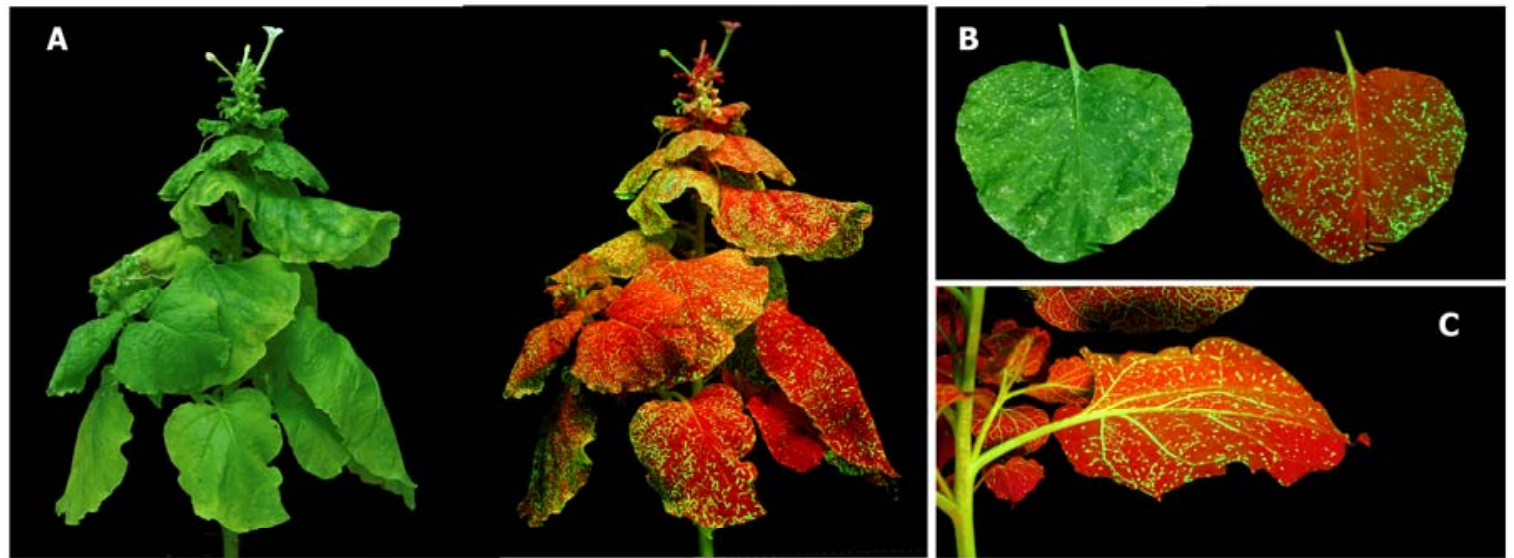

D
Phloem
restricted

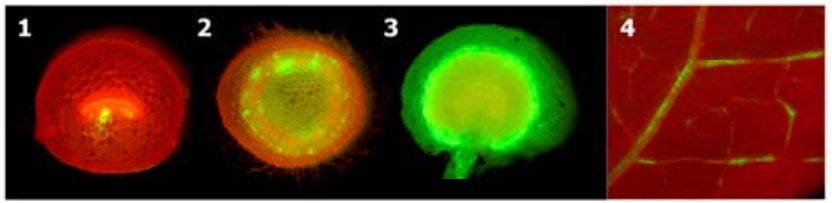

E
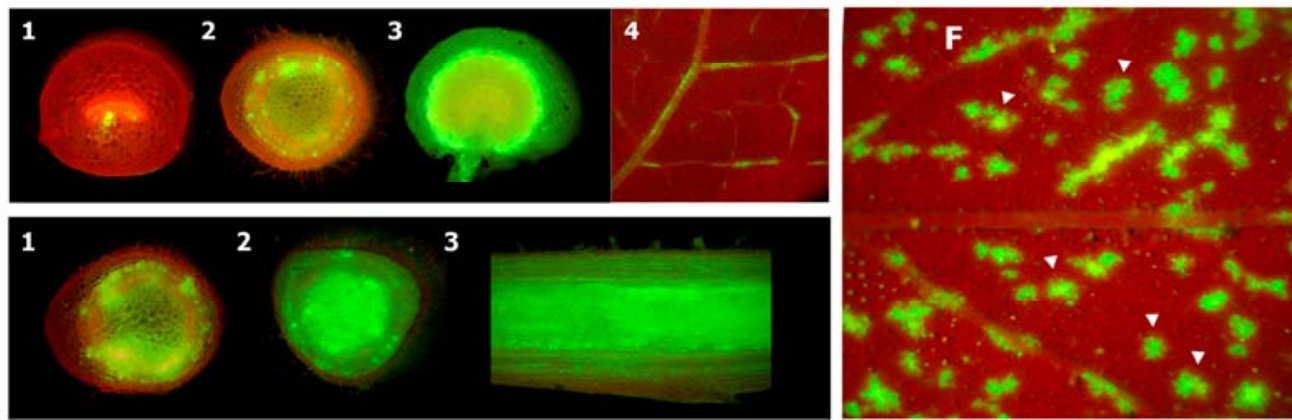

Fig. 4. Systemic spread and distribution of Citrus tristeza virus (CTV) in Nicotiana benthamiana after agroinfiltration with Panel I, constructs BBAC31Rint or Panel II, pCAM9R-GFP. I, A and B, Symptom expression and D and E, CTV distribution in a N. benthamiana plant systemically infected. A, Infected plant (right) showing leaf epinasty and vein chlorosis in comparison with a healthy control (left). B, Medium leaf showing vein necrosis. C, Negatively-stained, gradient-purified CTV virion from a systemically infected N. benthamiana plant (the bar indicates 500 nm). D, Tissueprint immunoblots from systemically infected $N$. benthamiana stem (1) and upper leaf petiole (2) at 1 month postinoculation (mpi), CTV-infected citrus leaf petiole (3) or healthy $N$. benthamiana leaf petiole (4). Purple-stained foci indicate the presence of CTV coat protein (CP) that, at this stage, is phloem-restricted. E, Similar tissue-print immunoblots from systemically infected $N$. benthamiana leaf petioles or stems at 2 mpi. General purple staining indicates that CTV has invaded nonphloem tissues. II, A and B, Symptom expression and A through F, CTV distribution in N. benthamiana plants infected with a green flourescent protein (GFP)-expressing CTV virus. A, Systemically infected N. benthamiana plant at 1 mpi, showing leaf epinasty and vein chlorosis under day light (left) or GFP fluorescence under UV light (right). B, Spatial association between vein chlorosis (left) and the presence of GFP fluorescence (right). C, Progress of CTV infection along stem, leaf petiole, and veins. D, CTV-GFP distribution in phloem tissue of young petiole (1), shoot (2), root (3), or leaf veins (4) in systemically infected $N$. benthamiana at 1 mpi. E, Distribution in shoots (1 and 2) and roots (3) at 2 mpi, showing the presence of the virus in nonphloem tissues. F, Distribution in leaves at 2 mpi, showing CTV accumulation in main veins and veinlets but also in mesophyll cells (arrowheads). 
tem based on $N$. benthamiana plants as intermediate host to produce virions by monitoring the kinetics of CTV accumulation in agroinfiltrated leaves. Former experiments with this system showed that mechanical inoculation of citrus plants with virion extracts from infiltrated leaves at 7 to 8 dpi was inefficient, likely due to low virus titers (Gowda et al. 2005). Here, we observed that CTV increase in these leaves continued until at least $3 \mathrm{wpi}$ and that the size and number of fluorescent foci in leaves agroinfiltrated with CTV-GFP also increased, suggesting that CTV not only replicated in $N$. benthamiana cells but it was able to move cell-to-cell. Yet, the movement into nonvascular cells was much more dramatic in the upper, systemically infected tissues. Movement of closteroviruses is known to occur after virion assembly (Alzhanova et al. 2001; Dolja 2003; Esau et al. 1967; Peremyslov et al. 2004), a process that requires the cooperation of at least four viral proteins
(Alzhanova et al. 2007; Napuli et al. 2003; Peremyslov et al. 2004; Satyanarayana et al. 2000). Additionally, the leader proteinases (Liu et al. 2009; Peng et al. 2001, 2002), the HSP70 homolog (Medina et al. 1999; Prokhnevsky et al. 2005), and the small transmembrane protein p6 (Alzhanova et al. 2000; Peremyslov et al. 2004; Tatineni et al. 2008) are required for cell-to-cell movement. Our finding that CTV-T36 can move cell-to-cell indicates that the above viral proteins properly interact with $N$. benthamiana factors involved in this process. Whether other CTV genotypes genetically distant from CTVT36 (Hilf et al. 2005; Martín et al. 2009; Moreno et al. 2008) are also capable of replication and movement in $N$. benthamiana plants remains to be proved.

Occurrence of systemic infection and symptoms in agroinfiltrated plants at 4 wpi or later was even more surprising. Systemic infection of $N$. benthamiana by agroinoculation of Beet

Table 2. Efficiency of systemic infection in Nicotiana benthamiana plants agroinfiltrated with a full-genome Citrus tristeza virus (CTV) cDNA clone using bacterial artificial chromosomes (BAC) or pCAMBIA plasmids and different silencing suppressor proteins

\begin{tabular}{|c|c|c|c|c|c|}
\hline \multirow[b]{2}{*}{ Clone } & \multicolumn{5}{|c|}{ Infectivity $^{\mathrm{a}}$} \\
\hline & None & $\mathbf{p 1 9}^{\mathbf{b}}$ & $\mathbf{p} 24^{c}$ & HC-Pro $^{d}$ & $\mathbf{p 2 3}^{\mathrm{e}}$ \\
\hline \multicolumn{6}{|l|}{ Section A } \\
\hline \multirow{6}{*}{ BBAC31Rint } & $4 / 6(5 / 6)$ & $3 / 3$ & $1 / 5$ & $3 / 4(4 / 4)$ & $3 / 4(4 / 4)$ \\
\hline & $4 / 5(5 / 5)$ & $3 / 3$ & $1 / 4(2 / 4)$ & $2 / 4(3 / 4)$ & $2 / 3(3 / 3)$ \\
\hline & $5 / 8(6 / 8)$ & $7 / 8(8 / 8)$ & & & $3 / 3$ \\
\hline & $2 / 4(3 / 4)$ & $4 / 4$ & $1 / 4$ & $2 / 5(3 / 5)$ & $2 / 3(3 / 3)$ \\
\hline & $1 / 5(2 / 5)$ & $5 / 5$ & $2 / 5(4 / 5)$ & $2 / 5(3 / 5)$ & $2 / 5(3 / 5)$ \\
\hline & $3 / 5$ & $4 / 5(5 / 5)$ & $2 / 5$ & $4 / 5(5 / 5)$ & $1 / 5(2 / 5)$ \\
\hline Mean $(\%)$ & $57.6(72.7)$ & $92.9(100)$ & $30.4(43.5)$ & $56.5(78.3)$ & $56.5(78.3)$ \\
\hline \multirow[t]{5}{*}{ BBAC31R } & $5 / 6(6 / 6)$ & $2 / 3$ & & & $3 / 4(4 / 4)$ \\
\hline & $1 / 4(2 / 4)$ & $2 / 4(4 / 4)$ & & & $1 / 3$ \\
\hline & $2 / 3(3 / 3)$ & $3 / 3$ & & & $3 / 3$ \\
\hline & $2 / 5(3 / 5)$ & $3 / 3$ & & & $3 / 3$ \\
\hline & $1 / 4$ & $4 / 4$ & & & \\
\hline Mean $(\%)$ & $50(68.2)$ & $82.4(94.1)$ & & & $76.9(84.6)$ \\
\hline \multirow[t]{6}{*}{ pCAM9R } & $0 / 4$ & $4 / 5(5 / 5)$ & $1 / 5(3 / 5)$ & & \\
\hline & $3 / 5(4 / 5)$ & $5 / 5$ & $4 / 5$ & & \\
\hline & $3 / 5(4 / 5)$ & $4 / 5(5 / 5)$ & $1 / 5(3 / 5)$ & & \\
\hline & $1 / 5(3 / 5)$ & $4 / 5$ & & & \\
\hline & $4 / 5(5 / 5)$ & $5 / 5$ & $3 / 5$ & & \\
\hline & $0 / 5(2 / 5)$ & & & & \\
\hline Mean (\%) & $37.9(62.1)$ & $88(96)$ & $45(65)$ & & \\
\hline \multirow{6}{*}{ pCAM9R-GFP } & $0 / 4$ & $6 / 7(7 / 7)$ & & & \\
\hline & $0 / 5$ & $3 / 5$ & $0 / 5(1 / 5)$ & & \\
\hline & $0 / 3$ & $3 / 4$ & $1 / 4(3 / 4)$ & & \\
\hline & $1 / 3$ & $2 / 3(3 / 3)$ & $1 / 3(2 / 3)$ & & \\
\hline & $1 / 7(5 / 7)$ & $4 / 6(5 / 6)$ & $1 / 7(6 / 7)$ & & \\
\hline & $2 / 5$ & $4 / 5$ & $1 / 5$ & & \\
\hline \multirow[t]{2}{*}{ Mean $(\%)$} & $14.8(29.6)$ & $73.3(83.3)$ & $25.8(54.8)$ & & \\
\hline & $p_{22}{ }^{f}$ & $\mathbf{p 1 9}^{\mathrm{b}}$ & $\mathbf{p 2 4}^{\mathrm{c}}$ & HC-Pro $^{\mathrm{g}}$ & p19+p22+p24+HC-Pro \\
\hline \multirow{9}{*}{$\begin{array}{l}\text { Section B } \\
\text { pCAM9R-GFP }\end{array}$} & & & & & \\
\hline & $10 / 14$ & & & & \\
\hline & $7 / 8$ & $4 / 8$ & $3 / 8$ & $4 / 8$ & $4 / 4$ \\
\hline & $5 / 8$ & $4 / 8$ & $1 / 8$ & $5 / 8$ & $\begin{array}{l}10 / 10 \\
7 / 8\end{array}$ \\
\hline & $3 / 8$ & $1 / 8$ & $\begin{array}{l}1 / 0 \\
5 / 8\end{array}$ & $\begin{array}{l}6 / 8 \\
6 / 8\end{array}$ & $7 / 9$ \\
\hline & $2 / 8$ & $1 / 8$ & $3 / 8$ & $7 / 8$ & $8 / 8$ \\
\hline & & & & & $48 / 48$ \\
\hline & & & & & $8 / 8$ \\
\hline & & & & & $6 / 6$ \\
\hline Mean $(\%)$ & 58.7 & 31.2 & 37.5 & 68.7 & 97 \\
\hline
\end{tabular}

${ }^{a}$ Expressed as the number of systemically infected plants to the number of agroinfiltrated plants and as the mean percentage of infected plants. Each row corresponds to a different experiment. In section A, infection in upper leaves was detected by enzyme-linked immunosorbent assay or fluorescence expression (CTV-GFP clones) at 4 to 6 weeks postinoculation (wpi) or at 8 wpi or later (within brackets). In section B, systemic infection was detected by discontinuous fluorescence in leaf veins at 3 wpi.

${ }^{\mathrm{b}}$ Coinfiltration with a vector expressing the 19 suppressor protein of Tomato bushy stunt virus.

${ }^{\mathrm{c}}$ Coinfiltration with a vector expressing the $\mathrm{p} 24$ protein of GLRaV2.

${ }^{\mathrm{d}}$ Coinfiltration with a vector expressing HC-Pro of Tobacco etch virus.

${ }^{\mathrm{e}}$ Coinfiltration with a vector expressing the $\mathrm{p} 23$ protein of CTV.

${ }^{\mathrm{f}}$ Coinfiltration with a vector expressing the $\mathrm{p} 22$ protein of Tomato chlorosis virus.

${ }^{\mathrm{g}}$ Coinfiltration with a vector expressing HC-Pro of Turnip mosaic virus.

${ }^{\mathrm{h}}$ Coinfiltration with a vector expressing a mix of cultures expressing $\mathrm{b}, \mathrm{d}$, $\mathrm{f}$, and g suppressors. 
yellows virus (BYV), Lettuce infectious yellows (LIYV), and GLRaV-2, also members of the family Closteroviridae, has been reported (Chiba et al. 2006; Liu et al. 2009; Prokhnevsky et al. 2002; Wang et al. 2009); however, while this species was known as an experimental systemic host for these viruses, it was considered a nonhost for CTV. Failure to infect $N$. benthamiana by mechanical inoculation with virion extracts may be related with the small number of viable particles reaching the cytoplasm and gRNA silencing before expression of the CTV silencing suppressors. Stunting, epinasty, and vein clearing and necrosis caused by CTV in systemically infected $N$. benthamiana plants resemble those incited in Mexican lime, which are diagnostic for CTV; however, crumple of young leaves is not observed in citrus, and seedling yellows, stem pitting, and tristeza decline symptoms, characteristic of different citrus species or scion-rootstock combinations (Moreno et al. 2008), cannot be observed in $N$. benthamiana. These findings suggest that, while some interactions between CTV and host factors inciting symptoms might be similar in citrus and $N$. bentha-
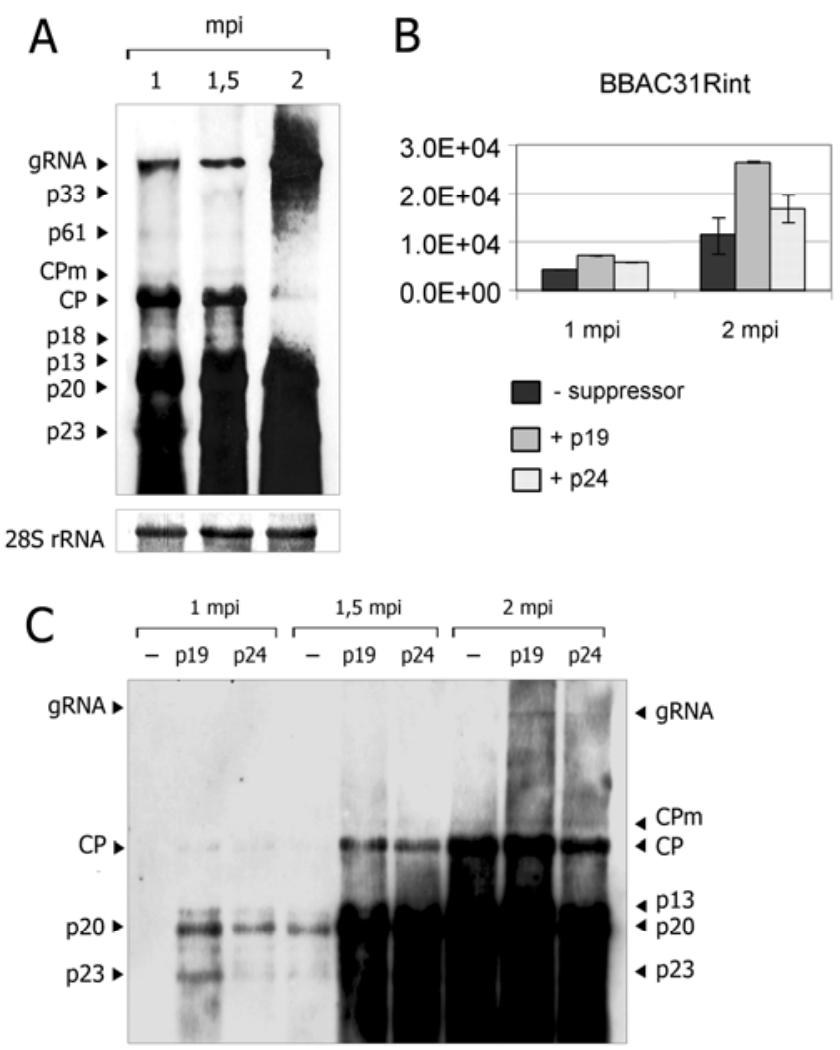

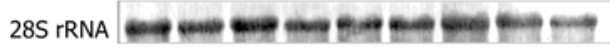

Fig. 5. Citrus tristeza virus (CTV) accumulation in new leaves of systemically infected Nicotiana benthamiana plants agroinfiltrated with or without silencing suppressors. A, Northern blot analysis of total RNA extracts (RNAt) $(3 \mu \mathrm{g})$ extracted at $1,1.5$, and 2 months postinoculation (mpi) from the upper leaves of $N$. benthamiana coinfiltrated with the construct CTV-BBAC31Rint and the silencing suppressor p19. Positions of the genomic (g)RNA and relevant subgenomic ( $\mathrm{sg}$ )RNAs are indicated by arrowheads. The membrane was hybridized with a digoxigenin-labeled riboprobe specific for the $3^{\prime}$ terminal region of the CTV gRNA. Methylene blue staining of the membrane shows the 28S rRNA used as loading control. B, Number of CTV gRNA copies per nanogram of RNAt from new leaves of systemically infected $N$. benthamiana plants at 1 or 2 mpi, measured by quantitative reverse transcription-polymerase chain reaction (RuizRuiz et al. 2007). Means and standard deviations were obtained from four technical replicates in two different bioassays. C, Northern blot analysis of RNAt $(3 \mu \mathrm{g})$ extracted from new leaves of systemically infected $N$. benthamiana at $1,1.5$, and $2 \mathrm{mpi}$, with the construct pCAM9R alone or with silencing suppressors p19 or p24. Other details as outlined in A. miana, others must be host-specific, in agreement with previous observations that ectopically expressed p23 incites CTVlike symptoms only in citrus plants (Fagoaga et al. 2005).

Since $A$. tumefaciens can systemically spread in several host species (Cubero et al. 2006), the presence of CTV in upper $N$. benthamiana leaves could be due to movement of the bacterium followed by local expression of CTV; however, failure to PCR-amplify a bacterial sequence out of the infiltrated leaf area does not support this hypothesis. It seems more likely that the potential long-distance movement factors of CTV-T36 are capable of proper interactions with $N$. benthamiana factors to allow systemic infection and that this would account for most, if not all, CTV accumulation in the upper leaves.

Systemic infection was obtained using a high or a low copynumber vector to deliver the CTV genome, and with or without coinfiltration with a vector expressing a silencing suppressor, albeit the ratio of systemically infected plants and the time elapsed between agroinfiltration and virus detection in the upper leaves was variable among experiments. The main advantage of using a low copy-number vector like BIBAC2 and an intron inserted in the CTV cDNA is that it can be easily manipulated in the lab without the bacterial toxicity and plasmid reorganization problems often found with CTV cDNA cloned in high copy-number vectors. Also, although the number of primary infections is greatly increased in plants coinfiltrated with a silencing suppressor, as previously observed with BYV (Chiba et al. 2006), the efficiency of systemic infection seems less affected by this factor, in agreement with results obtained with LIYV (Wang et al. 2009). A high ratio of systemically infected plants (almost 100\%) was achieved in about three weeks, coinfiltrating plants with a mix of four silencing suppressors, a period that was reduced to less than 2 wpi when the p22 suppressor of the crinivirus ToCV (Cañizares et al. 2008) was expressed in cis in the nucleus of the plant cells by cloning it in the CTV-expressing vector. To our knowledge, this is the first time that expression of a silencing suppressor in cis has been used to improve agroinoculation of a plant virus. These results provide a genetic system for CTV that is easier, faster, and more reliable than protoplast transfection with RNA

Table 3. Infectivity of Citrus tristeza virus (CTV) virions obtained from systemically infected Nicotiana benthamiana on mechanically inoculated alemow plants

\begin{tabular}{lll}
\hline Inoculum source & Virions $^{\mathbf{a}}$ & Crude sap $^{\mathbf{b}}$ \\
\hline Upper leaves from $N$. benthamiana agroinfiltrated with & \\
BBAC31Rint clone & $2 / 3$ & $1 / 4$ \\
& $3 / 4$ & $2 / 7(3 / 7)$ \\
& $3 / 4(4 / 4)$ & $3 / 20(4 / 20)$ \\
Mean (\%) & $4 / 4$ & $1 / 4(2 / 4)$ \\
BBAC31R clone & $80(86.7)$ & $20(28.6)$ \\
& $2 / 4$ & $1 / 5$ \\
& $1 / 3$ & $1 / 4(2 / 4)$ \\
Mean $(\%)$ & $3 / 4(4 / 4)$ & \\
pCAM9R clone & $4 / 4$ & $22.2(33.3)$ \\
& $66.7(73.3)$ & \\
Mean $(\%)$ & $4 / 4$ & \\
Control ${ }^{\mathrm{c}}$ & $3 / 4$ & \\
& $4 / 5$ & \\
Mean $(\%)$ & 84.6 & \\
\hline
\end{tabular}

${ }^{a}$ Gradient purified virions. Infectivity expressed as the number of infected citrus plants to the number of inoculated plants at 1 to 1.5 months postinoculation (mpi) and as the mean percentage of infected plants. Numbers within brackets indicate infectivity at $3 \mathrm{mpi}$ or later.

${ }^{\mathrm{b}}$ Infectivity at 2 or $\geq 3 \mathrm{mpi}$ (within brackets).

${ }^{c}$ Citrus bark infected with CTV 947R 
transcripts (Satyanarayana et al. 1999, 2001). Agroinfiltration of $N$. benthamiana plants does not require preparation of RNA transcripts and protoplasts, avoids loss of experiments due to protoplast contamination, and reduces to one fourth or less the time necessary to obtain enough CTV virions to mechanically inoculate citrus plants.

Systemic infection of $N$. benthamiana plants was critical for the last step of the genetic system, i.e., efficient infection of citrus plants by slash-inoculation with virion extracts. Early experiments using virion extracts from agroinfiltrated leaves at 7 to 8 dpi (Gowda et al. 2005) were usually unsuccessful, due to low virus accumulation during this period. Indeed time-course accumulation measures showed a 15- to 30-fold increase of CTV titers in agroinfiltrated leaves between 1 and $3 \mathrm{wpi}$, sometimes reaching the threshold titer for successful transmission to citrus (about $5 \times 10^{3}$ to $10 \times 10^{3}$ gRNA copies per nanogram of RNAt). Virion accumulation in the upper leaves was higher, particularly after $7 \mathrm{wpi}$, when CTV invaded not only the phloem but other parenchyma tissues as well. This high virion concentration enabled easy transmission to citrus, even using crude leaf extracts. Contrasting with $N$. benthamiana, citrus plants infected with the same virions showed a normal CTV distribution strictly restricted to the phloem, indicating that passage through $N$. benthamiana did not alter movement characteristics of CTV in citrus. This distribution is likely related to the strong silencing reaction incited by CTV infection in citrus (Fagoaga et al. 2006), and it can be partially counteracted by ectopic expression of the p23 silencing suppressor in transgenic plants (Fagoaga et al. 2011). Unrestricted spread of CTV in $N$. benthamiana in advanced stages of the infection suggests a weaker silencing reaction from this host in comparison with citrus, perhaps due to the lack of an active salicylic acid- and virus-inducible RNA-dependent RNA polymerase (NbRdRPIm) involved in silencing of some viruses that makes $N$. benthamiana very susceptible to those viruses (Yang et al. 2004).

In summary, agroinfiltration of CTV-T36 to N. benthamiana plants provided the first herbaceous experimental host for this closterovirus that, in nature, is restricted to citrus. Although CTV was aphid transmitted to Passiflora gracilis and P. caerulea (Müller et al. 1974; Roistacher and Bar-Joseph 1987), these are perennial vines that offer no experimental advantage compared to citrus. Availability of a well known herbaceous systemic host for which molecular information is rapidly increasing will be a most useful tool to start dissecting CTV-host interactions, particularly those related to within-plant movement and symptom expression. The high virus accumulation in systemically infected leaves makes it easy to assay new mutants in citrus within a workable time.

\section{MATERIALS AND METHODS}

\section{Virus source and plant growth.}

The isolate $947 \mathrm{R}$ is a clonal virus population obtained from a cDNA clone of the CTV genotype T36 from Florida that has biological characteristics indistinguishable from the wild CTVT36 (Satyanarayana et al. 2001). Isolate 947R is maintained in Mexican lime and alemow seedlings in a contained, temperature-controlled $\left(18^{\circ} \mathrm{C}\right.$ night and $26^{\circ} \mathrm{C}$ day) greenhouse. Citrus plants were grown in an artificial potting mix (50\% peat moss, $50 \%$ sand) and were fertilized by a standard procedure. $N$. benthamiana plants were grown in a customized growth chamber kept at 23 to $24^{\circ} \mathrm{C}$ constant temperature and 50 to $60 \%$ relative humidity with a 16-h light and 8-h dark photoperiod.

\section{RNA extraction.}

Extracts enriched in CTV dsRNA were obtained from 5 to $10 \mathrm{~g}$ of citrus bark as reported previously (Moreno et al. 1990).
RNAt were prepared from 1 to $3 \mathrm{~g}$ of young citrus bark or from 100 to $300 \mathrm{mg}$ of $N$. benthamiana leaf by grinding tissue to powder with liquid nitrogen and, then, using a standard phenol-chloroform-isoamyl alcohol extraction protocol (RuizRuiz et al. 2007) or the RNeasy plant mini kit (Qiagen, GmbH Qiagen, Hilden, Germany). When needed, RNA was further purified with the RNeasy cleanup kit (Qiagen) and was resuspended in $25 \mu \mathrm{l}$ of RNase-free water, and in all cases, was treated with RNase-free DNase (Turbo DNA-free, Ambion, Inc., Applied Biosystems, Austin, TX, U.S.A.) before using it as template for RT-PCR or real-time qRT-PCR amplification assays.

\section{Plasmid constructs, binary plasmids and bacterial strains.}

A pUC119 vector was initially modified by site-directed mutagenesis to introduce a set of suitable restriction sites, two external SfiI sites flanking a StuI-MluI-SmaI minilinker. Plasmid pUC35S-8 (Fig. 1B) was generated from this modified pUC119 after three subcloning steps: i) a double-enhanced $35 \mathrm{~S}$ promoter $(35 \mathrm{~S} \times 2)$ of the $\mathrm{CaMV}$ was $\mathrm{PCR}$-amplified from a pKYLK plasmid (plasmid p35Se-NOS-B provided by J. J. López-Moya, C.S.I.C., Barcelona, Spain) and was ligated as a PstI-blunt ended fragment after Pst $\mathrm{I}-$ StuI digestion of the plasmid, ii) the NOS-t from the plasmid pBI101 was excised and cloned as a $S a c \mathrm{I}-E c o$ RI fragment, and iii) the antigenomic ribozyme sequence of the Hepatitis delta virus was PCRamplified from vector 2.0 (provided by A. Ball, University of Alabama, Birmingham, U.S.A.), and then, was cloned as a blunt end SacI fragment into the SmaI-SacI-digested plasmid.

The full-genome CTV cDNA clone p35SC31 was assembled into the new pUC35S-8 vector by three successive cloning steps. Two cDNA fragments (Fig. 1A, fragments A and B) were PCR-amplified, using appropriate primers based on the T36 nucleotide sequence (U16304) and the pCTV9 infectious clone as template (Satyanarayana et al. 1999, 2001). The two fragments were successively cloned in pUC35S-8; fragment A spanning the $5^{\prime}$ terminal 3,703 nt was MluI-digested and was inserted into the StuI-MluI digested pUC35S-8 vector, and then, fragment B spanning nucleotides 14,773 to 19,296 was MluI-digested and was inserted into the SmaI-MluI-digested vector containing fragment A. Finally, an internal MluI fragment derived from pCTV9 plasmid (Fig. 1A, fragment C) was cloned into the appropriately digested vector to engineer the full-length clone. Minireplicon p35S $\Delta \mathrm{Cla} 9$ was generated from the full-genome clone p35SC31 by a large ClaI internal deletion, as previously described (Satyanarayana et al. 1999). A version of this replicon with the frameshift at position 3,732 properly restored was synthesized as reported by Satyanarayana and associates (2003) to obtain the vector p35S $\Delta$ Cla295R (Fig. 1D).

To reduce bacterial toxicity of the restored CTV sequence, an intron was inserted in the toxic region (Satyanarayana et al. 2003) to disrupt ORF 1a. The intron 2 sequence of the ST-LS1 gene from potato (Eckes et al. 1986) was PCR-amplified from the p35S-GUSintron plasmid (Vancanneyt et al. 1990), using a set of primers designed to optimize the consensus sequences for splicing in plants. The intron sequence was introduced at nucleotide positions 3,652 or 3,744 in the CTV genome, using an overlap-extension PCR technique (Ho et al. 1989) (Fig. 1D). The amplified fragment was digested and cloned between unique restriction sites $M l u \mathrm{I}$ and $X b a \mathrm{I}$, present in p35S $\Delta$ Cla295R, to obtain the construct p35S $\Delta$ Cla295Rint. A SmaI-NotI cDNA fragment obtained after digestion of the clone p35SC31 was ligated into the similarly digested p35S $\Delta$ Cla295Rint vector to obtain the full-length construct p35SC31Rint. The CTV full-length cDNA clones pCTV9, pCTV9R, and those derived from them were grown in E. coli 
JM109 as described previously (Satyanarayana et al. 1999, 2001). The size of the E. coli colonies was measured with a stereoscopic microscope at 1 and 2 days after plating.

Binary plasmids pBIN19, pCAMBIA1380, and BIBAC2 were utilized for agroinoculation experiments. Clones pBINCTV9 and pBIN $\Delta$ Cla9 were obtained after SfiI-digestion of p35SC31 and p35S $\Delta$ Cla9 plasmids, respectively, followed by ligation into the SfiI-restricted vector pBIN19-SfiI L3.7, a modified version of pBIN19-sGFP (Chiu et al. 1996) obtained by addition of a $S f i \mathrm{I}$ site. Constructs pCAM $\Delta$ Cla14R and pCAM9R, based on the pCAMBIA1380 plasmid, have been described previously (Gowda et al. 2005). The gene for GFP expression (GFP-C3 version) was inserted into the sequence of the CTV9R cDNA, between the CP and CPm ORF under the BYV CP controller element (Folimonov et al. 2007; Tatineni et al. 2008), in order to obtain the pCAM9R-GFP vector. The BIBAC2 vector $(22.5 \mathrm{~kb})$ replicates in E. coli and A. tumefaciens cells, and it contains two NotI sites flanking the unique BamHI cloning site and selectable markers for resistance to kanamycin (neomycin phosphotransferase II) and hygromicin (hygromycin phosphotransferase) (Hamilton 1997) (Fig. 1E). Unless otherwise indicated, CTV expression cassettes were excised from the plasmid with $S f i$, were ligated to synthetic SfiI linkers containing an internal NotI site, and were then digested with the latter enzyme. The CTV NotI-restricted cassettes were then ligated to purified NotI-restricted BIBAC2 plasmid, and the ligation mix was used to transform E. coli DH10B competent cells by electroporation with a Gene Pulser (Bio-Rad Laboratories, Inc., Hercules, CA, U.S.A.). Transformed cells were selected on LB plates containing kanamycin ( $80 \mathrm{mg} / \mathrm{liter}$ ) and sucrose (5 to $10 \%$ ). About 20 to $50 \mathrm{ng}$ of plasmid, purified by standard BAC-miniprep, were used to transform the $A$. tumefaciens COR308 strain (UIA143 pMP90 pCH32; Hamilton 1997) by electroporation. The helper plasmid $\mathrm{pCH} 32$ carries additional copies of virG, virE1, and virE2 genes from $A$. tumefaciens, and it is selected on LB medium containing $10 \mathrm{mg}$ of tetracycline per liter. A. tumefaciens EHA105 was also used in some experiments. Transfected cells were selected on LB medium containing kanamycin (50 $\mathrm{mg} / \mathrm{liter}$ ) and nalidixic acid (20 mg/liter). Occasionally, some oncogenic A. tumefaciens strains were used, selecting them with appropriate antibiotics. Additional details on the constructs can be supplied by the authors upon request.

\section{Agroinoculation and CTV detection.}

In general, colonies of A. tumefaciens (strain COR 308) transfected with BBAC, pBIN, or pCAMBIA plasmids carrying the full-length CTV cDNA were grown overnight at $28^{\circ} \mathrm{C}$ in LB medium supplemented with $50 \mathrm{mg}$ of kanamycin per liter, $5 \mathrm{mg}$ of tetracycline per liter, $10 \mathrm{mM}$ MES (morpholineethanesulfonic acid), and $20 \mu \mathrm{M}$ acetosyringone. Bacteria were collected by centrifugation at $6,000 \times g$ for $15 \mathrm{~min}$ at room temperature, were resuspended in LB medium supplemented with $10 \mathrm{mM} \mathrm{MgCl} 2,10 \mathrm{mM}$ MES, pH 5.6, and 150 $\mu \mathrm{M}$ acetosyringone, and the concentration was adjusted to an optical density at $600 \mathrm{~nm}$ value of 1 . After 3 to $5 \mathrm{~h}$ of induction in this medium, bacterial suspensions were infiltrated on fully expanded $N$. benthamiana or citrus leaves using a syringe. In coinfiltration experiments, $A$. tumefaciens cultures transfected with CTV-carrying binary plasmids (or empty plasmids) and others transfected with plasmids expressing silencing suppressor proteins were mixed in a 2:1 ratio (CTV clone/silencing suppressor) prior to infiltration.

CTV infection in $N$. benthamiana was monitored in the infiltrated leaves by double-antibody sandwich-ELISA using a mix of monoclonal antibodies 3DF1 and 3CA5 (Vela et al. 1986), by RT-PCR techniques, Northern blot analysis, or fluo- rescence observation (when CTV-GFP was used) once a week during the first month after inoculation, and then, every one or two weeks in the upper leaves. GFP fluorescence was generally observed with a long-wavelength UV light hand-lamp (Black Ray model B100AP, UV products, Upland, CA, U.S.A.) and was photographed using a Canon G7 digital camera combined with a yellow filter. In each experiment, Northern blot and RT-PCR detection and quantification (discussed below) were performed on a pool of leaf fragments from all plants of the same treatment. Data provided are from at least two independent experiments with at least two replicates. Images of fluorescence distribution in infected tissues were taken with a Leica stereoscope (Leica, Heidelberg, Germany) provided with UV illumination and a GFP filter. Immunosorbent electron microscopy was performed as described by Milne (1993), using the monoclonal antibodies 3DF1 and 3CA5, and the grids were examined in a Philips 100 CM10 electron microscope at $80 \mathrm{kV}$.

\section{Northern blot analysis.}

For Northern blot analysis of CTV RNA, RNAt aliquots (3 to $5 \mu \mathrm{g}$ ) were separated by $1 \%$ formaldehyde agarose gel electrophoresis in MOPS (morpholinepropanesulfonic acid) buffer, were electroblotted onto positively charged nylon membranes (Roche Diagnostics, F. Hoffmann-La Roche AG, Basel, Switzerland), and were hybridized with a digoxigenin-labeled riboprobe specific for the $3^{\prime}$ terminal region of the CTV genome (Satyanarayana et al. 1999).

\section{RT-PCR and qRT-PCR.}

Correct splicing of the intron inserted in the CTV cDNA after agroinoculation and transcription in the plant nucleus was checked by RT-PCR, using primers PM118 (5'-GTGTTATCATGCATCGGAGGCG-3') and PM119 (5'-ACCGGGGAATTTTGATTCTAATC- $3^{\prime}$ ) directed to regions flanking the intron insertion point in the CTV gRNA (positions 3,652 and 3,744 in the CTV-T36 sequence). RT was performed using these primers, $1 \mu \mathrm{g}$ of DNase-treated RNAt and SuperScript II reverse transcriptase (Invitrogen Life Technologies, Carlsbad, CA, U.S.A.), in the conditions reported (Ruiz-Ruiz et al. 2006). A control reaction without reverse transcriptase was carried out for each sample. PCR amplification was performed in a 50- $\mu$ l reaction mix containing a $1-\mu 1$ aliquot of the RT reaction, primers PM118 and PM119, and Taq DNA polymerase (Roche Diagnostics) (Ruiz-Ruiz et al. 2006). Negative controls included reactions using water instead of RNAt or RNAt extracts from healthy plants or from plants agroinfiltrated with an empty binary vector, whereas similar reactions with RNAt or dsRNArich extracts from CTV-infected citrus plants or plasmid DNA containing CTV cDNA with or without the intron were used as positive control. PCR amplification with primers PM118 and PM119 is expected to yield DNA fragments of $622 \mathrm{bp}$ with the intron-containing template or 433 bp with the intronless template. PCR products were purified using the GeneClean kit (QBiogene, Inc, Carlsbad, CA, U.S.A.) and were sequenced in both directions to confirm the correct RNA splicing in planta.

Quantitative assays (qRT-PCR) were performed in a LightCycler platform (Roche Diagnostics) with $20-\mu 1$ glass capillaries in the conditions reported (Ruiz-Ruiz et al. 2007). In each run, control samples included RNAt from healthy citrus or $N$. benthamiana, water instead of RNAt extract, and at least one RNA transcript dilution of the standard curve. Also, for each plant extract, real-time RT-PCR with and without reverse transcriptase were run in parallel to ensure the absence of binary plasmid DNA or other contaminant DNA template. The absolute number of T36 gRNA copies per nanogram of RNAt was estimated using an external standard curve prepared with RNA 
transcripts including the amplified region, as described previously (Ruiz-Ruiz et al. 2007).

\section{Indexing in indicator plants.}

The infectivity of CTV virions generated in agroinfiltrated $N$. benthamiana leaves or in plants systemically infected was tested by slash-inoculation of four or five alemow plants (Garnsey et al. 1977) using gradient purified extracts (Satyanarayana et al. 2001) or crude sap extracts as indicated. A similar number of indicator plants was inoculated with virion extracts from citrus plants infected with the 947R isolate of CTV-T36 as control. CTV infection in the new leaves was detected at 1 to 2 mpi by ELISA.

\section{ACKNOWLEDGMENTS}

This work was supported by grants AGL2007-61885/AGR and AGL2010-20221, cofinanced by FEDER (European Fund for Regional Development) funds and by the Ministerio de Ciencia e Innovación (MICINN), and project 5953 from the IVIA (Instituto Valenciano de Investigaciones Agrarias). S. Ambrós was the recipient of contracts from the Ramón y Cajal program of the Ministerio de Educación y Ciencia, the Agroalimed Foundation, and the IVIA (Generalitat Valenciana). C. ElMohtar was funded in part by a grant from the Citrus Research and Development Foundation and an endowment from the J. R. and Addie Graves family.

\section{LITERATURE CITED}

Alzhanova, D. V., Hagiwara, Y., Peremyslov, V. V., and Dolja, V. V. 2000. Genetic analysis of the cell-to-cell movement of Beet yellows closterovirus. Virology 268:192-200.

Alzhanova, D. V., Napuli, A. J., Creamer, R., and Dolja, V. V. 2001. Cellto-cell movement and assembly of a plant closterovirus: Roles for the capsid proteins and Hsp70 homolog. EMBO (Eur. Mol. Biol. Organ.) J. 20:6997-7007.

Alzhanova, D. V., Prokhnevsky, A. I., Peremyslov, V. V., and Dolja V. V. 2007. Virion tails of Beet yellows virus: Coordinated assembly by three structural proteins. Virology 359:220-226.

Bar-Joseph, M., and Dawson, W. O. 2008. Citrus tristeza virus. Pages 520525 in: Encyclopedia of Virology. B. W. J. Mahy and M. H. V. Van Regenmortel, eds. Elsevier, Oxford.

Bar-Joseph, M., and Lee, R. F. 1989. Citrus tristeza virus, No. 353 in: AAB Descriptions of Plant Viruses. A. F. Murant and B. D. Harrison, eds. Association of Applied Biologists. Wellesbourne, Warwick, U.K.

Cañizares, M. C., Navas-Castillo, J., and Moriones, E. 2008. Multiple suppressors of RNA silencing encoded by both genomic RNAs of the crinivirus Tomato chlorosis virus. Virology 379:168-174.

Chiba, M., Reed, J. C., Prokhnevsky, A. I., Chapman, E. J., Mawassi, M., Koonin, E. V., Carrington, J. C., and Dolja, V. V. 2006. Diverse suppressors of RNA silencing enhance agroinfection by a viral replicon. Virology 346:7-14.

Chiu, W., Niwa, Y., Zeng, W., Hirano, T., Kobayashi, H., and Sheen, J. 1996. Engineered GFP as a vital reporter in plants. Curr. Biol. 6:325-330.

Cubero, J., Lastra, B., Salcedo, C. I., Piquer, J., and López, M. 2006. Systemic movement of Agrobacterium tumefaciens in several plant species. J. Appl. Microbiol. 101:412-421.

Dolja, V. V. 2003. Beet yellows virus: The importance of being different. Mol. Plant Pathol. 4:91-98.

Dolja, V. V., Kreuze, J. F., and Valkonen, J. P. 2006. Comparative and functional genomics of closteroviruses. Virus Res. 117:38-51.

Eckes, P., Rosahl, S., Schell, J., and Willmitzer, L. 1986. Isolation and characterization of a light-inducible, organ-specific gene from potato and analysis of its expression after tagging and transfer into tobacco and potato shoots. Mol. Gen. Genetics 205:14-22.

Esau, K., Cronshaw, J., and Hoefert, L. L. 1967. Relation of beet yellows virus to the phloem and to movement in the sieve tube. J. Cell Biol. 32:71-87.

Fagoaga, C., López, C., Moreno, P., Navarro, L., Flores, R., and Peña, L. 2005. Viral-like symptoms induced by the ectopic expression of the p23 gene of Citrus tristeza virus are citrus specific and do not correlate with the pathogenicity of the virus strain. Mol. Plant-Microbe Interact. 18:435-445

Fagoaga, C., López, C., Hermoso de Mendoza, A., Moreno, P., Navarro, L., Flores, R., and Peña, L. 2006. Post-transcriptional gene silencing of the p23 silencing suppressor of Citrus tristeza virus confers resistance to the virus in transgenic Mexican lime. Plant Mol. Biol. 60:153-165.
Fagoaga, C., Pensabene-Bellavia, G., Moreno, P., Navarro, L., Flores, R. and Peña, L. 2011. Ectopic expression of the p23 protein of Citrus tristeza virus differentially modifies viral accumulation and tropism in two transgenic woody hosts. Mol. Plant Pathol. doi: 10.1111/J.13643703.2011.00722.X

Folimonov, A. S., Folimonova, S. Y., Bar-Joseph, M., and Dawson, W. O. 2007. A stable RNA virus-based vector for citrus trees. Virology 368:205-216.

Garnsey, S. M., Gonsalves, D., and Purcifull, D. E. 1977. Mechanical transmission of citrus tristeza virus. Phytopathology 67:965-968.

Gowda, S., Satyanarayana, T., Ayllón, M. A., Albiach-Martí, M. R. Mawassi, M., Rabindran, S., Garnsey, S. M., and Dawson, W. O. 2001 Characterization of the cis-acting elements controlling subgenomic mRNAs of Citrus tristeza virus: Production of positive- and negativestranded 3'-terminal and positive-stranded 5'-terminal RNAs. Virology 286:134-151

Gowda, S., Satyanarayana, T., Robertson, C. J., Garnsey, S. M., and Dawson, W. O. 2005. Infection of citrus plants with virions generated in Nicotiana benthamiana plants agroinfiltrated with a binary vector based Citrus tristeza virus. Pages 23-33 in: Proceedings of the 16th Conference of the International Organization of Citrus Virologists. M. E. Hilf, N. Duran-Vila, and M. A. Rocha-Peña, eds. International Organization of Citrus Virologists, Riverside, CA, U.S.A.

Gowda, S., Tatineni, S., Folimonova, S. Y., Hilf, M. E., and Dawson, W. O. 2009. Accumulation of a $5^{\prime}$ proximal subgenomic RNA of Citrus tristeza virus is correlated with encapsidation by the minor coat protein. Virology 389:122-131.

Grimsley, N., Hohn, B., Hohn, T., and Walden, R. 1986. Agroinfection, an alternative route for viral-infection of plants by using the Ti plasmid. Proc. Natl. Acad. Sci. U.S.A. 83:3282-3286.

Hamilton, C. M. 1997. A binary-BAC system for plant transformation with high-molecular-weight DNA. Gene 200:107-116.

Hilf, M. E., Karasev, A. V., Pappu, H. R., Gumpf, D. J., Niblett, C. L., and Garnsey, S. M. 1995. Characterization of citrus tristeza virus subgenomic RNAs in infected tissue. Virology 208:576-582.

Hilf, M. E., Mavrodieva, V. A., and Garnsey, S. M. 2005. Genetic marker analysis of a global collection of isolates of Citrus tristeza virus: Characterization and distribution of CTV genotypes and association with symptoms. Phytopathology 95:909-917.

Ho, S. N., Hunt, H. D., Horton, R. M., Pullen, J. K., and Pease, L. R. 1989 Site-directed mutagenesis by overlap extension using polymerase chain reaction. Gene 77:51-59.

Johansen, I. E. 1996. Intron insertion facilitates amplification of cloned virus cDNA in Escherichia coli while biological activity is reestablished after transcription in vivo. Proc. Natl. Acad. Sci. U.S.A. 93:12400-12405.

Karasev, A. V., Boyko, V. P., Gowda, S., Nikolaeva, O. V., Hilf, M. E., Koonin, E. V., Niblett, C. L., Cline, K., Gumpf, D. J., Lee, R. F., Garnsey, S. M., Lewandowski, D. J., and Dawson, W. O. 1995. Complete sequence of the Citrus tristeza virus RNA genome. Virology 208:511-520.

Leiser, R. M., Ziegler-Graff, V., Reutenauer, A., Herrbach, E., Lemaire, O., Guilley, H., Richards, K., and Jonard, G. 1992. Agroinfection as an alternative to insects for infecting plants with beet western yellows luteovirus. Proc. Natl. Acad. Sci. U.S.A. 89:9136-9140.

Liu, Y. P., Peremyslov, V. V., Medina, V., and Dolja, V. V. 2009. Tandem leader proteases of Grapevine leafroll-associated virus-2: Host-specific functions in the infection cycle. Virology 383:291-299.

Lu, R., Folimonov, A., Shintaku, M., Li, W. X., Falk, B. W., Dawson, W. O., and Ding, S. W. 2004. Three distinct suppressors of RNA silencing encoded by a $20-\mathrm{kb}$ viral RNA genome. Proc. Natl. Acad. Sci. U. S. A 101:15742-15747.

Martín, S., Sambade, A., Rubio, L., Vives, M. C., Moya, P., Guerri, J., Elena, S. F., and Moreno, P. 2009. Contribution of recombination and selection to molecular evolution of Citrus tristeza virus. J. Gen. Virol. 90:1527-1538.

Medina, V., Peremyslov, V. V., Hagiwara, Y., and Dolja, V. V. 1999. Subcellular localization of the HSP70-homolog encoded by beet yellows closterovirus. Virology 260:173-181.

Milne, R. G. 1993. Electron microscopy of in vitro preparations. Pages 215-251 in: Diagnosis of plant virus diseases. R. E. F. Matthews, ed. CRC Press, Boca Ratón, FL, U.S.A.

Moreno, P., Guerri, J., and Muñoz, N. 1990. Identification of Spanish strains of Citrus tristeza virus by analysis of double-stranded-RNA. Phytopathology 80:477-482.

Moreno, P., Ambrós, S., Albiach-Martí, M. R., Guerri, J., and Peña, L. 2008. Plant diseases that changed the world-Citrus tristeza virus: A pathogen that changed the course of the citrus industry. Mol. Plant Pathol. 9:251-268.

Moreno, P. and Garnsey, S. M. 2010. Citrus tristeza diseases: A worlwide perspective. Pages 27-49 in: Citrus tristeza virus complex and tristeza 
diseases. A. V. Karasev and M. E. Hilf, eds. The American Phytopathological Society, St. Paul, MN, U.S.A.

Müller, G. W., Costa, A. S., Kitajima, E. W., and Camargo, I. J. B. 1974. Additional evidence that tristeza virus multiplies in Passiflora spp. Pages 75-78 in: Proceedings of the 6th Conference of the International Organization of Citrus Virologists. L. G. Weathers, ed. University of California, Division of Agricultural Sciences, Berkeley, CA, U.S.A.

Müller, G. W., and Garnsey, S. M. 1984. Susceptibility of citrus varieties, species, citrus relatives, and non-rutaceous plants to slash-cut mechanical inoculation with Citrus tristeza virus (CTV). Pages 33-40 in: Proceedings of the 9th Conference of the International Organization of Citrus Virologists, S. M. Garnsey, L. W. Timmer, and J. A. Dodds, eds., International Organization of Citrus Virologists, Riverside, CA, U.S.A.

Napuli, A. J., Alzhanova, D. V., Doneanu, C. E., Barofsky, D. F., Koonin, E. V., and Dolja, V. V. 2003. The 64-kilodalton capsid protein homolog of Beet yellows virus is required for assembly of virion tails. J. Virol. 77:2377-2384.

Navas-Castillo, J., Albiach-Martí, M. R., Gowda, S., Hilf, M. E., Garnsey, S. M., and Dawson, W. O. 1997. Kinetics of accumulation of Citrus tristeza virus RNAs. Virology 228:92-97.

Peng, C. W., Peremyslov, V. V., Mushegian, A. R., Dawson, W. O., and Dolja, V. V. 2001. Functional specialization and evolution of leader proteinases in the family Closteroviridae. J. Virol. 75:12153-12160.

Peng, C. W., Peremyslov, V. V., Snijder, E. J., and Dolja, V. V. 2002. A replication-competent chimera of plant and animal viruses. Virology 294:75-84.

Peremyslov, V. V., Andreev, I. A., Prokhnevsky, A. I., Duncan, G. H., Taliansky, M. E., and Dolja, V. V. 2004. Complex molecular architecture of Beet yellows virus particles. Proc. Natl. Acad. Sci. U.S.A. 101:5030-5035.

Prokhnevsky, A. I., Peremyslov, V. V., Napuli, A. J., and Dolja, V. V. 2002. Interaction between long-distance transport factor and Hsp70-related movement protein of Beet yellows virus. J. Virol. 76:11003-11011.

Prokhnevsky, A. I., Peremyslov, V. V., and Dolja, V. V. 2005. Actin cytoskeleton is involved in targeting of a viral Hsp70 homolog to the cell periphery. J. Virol. 79:14421-14428.

Roistacher, C. N. and Bar-Joseph, M. 1987. Transmission of Citrus tristeza virus by Aphis gossypii and by graft inoculation to and from Passiflora spp. Phytophylactica 19:179-182.

Ruiz-Ruiz, S., Moreno, P., Guerri, J., and Ambrós, S. 2006. The complete nucleotide sequence of a severe stem pitting isolate of Citrus tristeza virus from Spain: Comparison with isolates from different origins. Arch. Virol. 151:387-398.

Ruiz-Ruiz, S., Moreno, P., Guerri, J., and Ambrós, S. 2007. A real-time RT-PCR assay for detection and absolute quantitation of Citrus tristeza virus in different plant tissues. J. Virol. Methods 145:96-105.

Satyanarayana, T., Gowda, S., Boyko, V. P., Albiach-Martí, M. R., Mawassi, M., Navas-Castillo, J., Karasev, A. V., Dolja, V., Hilf, M. E. Lewandowski, D. J., Moreno, P., Bar-Joseph, M., Garnsey, S. M., and Dawson, W. O. 1999. An engineered closterovirus RNA replicon and analysis of heterologous terminal sequences for replication. Proc. Natl.
Acad. Sci. U.S.A. 96:7433-7438.

Satyanarayana, T., Gowda, S., Mawassi, M., Albiach-Martí, M. R., Ayllón, M. A., Robertson, C., Garnsey, S. M., and Dawson, W. O. 2000. Closterovirus encoded HSP70 homolog and p61 in addition to both coat proteins function in efficient virion assembly. Virology 278:253-265.

Satyanarayana, T., Bar-Joseph, M., Mawassi, M., Albiach-Martí, M. R. Ayllón, M. A., Gowda, S., Hilf, M. E., Moreno, P., Garnsey, S. M., and Dawson, W. O. 2001. Amplification of Citrus tristeza virus from a cDNA clone and infection of citrus trees. Virology 280:87-96.

Satyanarayana, T., Gowda, S., Ayllón, M. A., and Dawson, W. O. 2003. Frameshift mutations in infectious cDNA clones of Citrus tristeza virus: A strategy to minimize the toxicity of viral sequences to Escherichia coli. Virology 313:481-491.

Satyanarayana, T., Gowda, S., Ayllón, M. A., and Dawson, W. O. 2004. Closterovirus bipolar virion: Evidence for initiation of assembly by minor coat protein and its restriction to the genomic RNA 5' region. Proc. Natl. Acad. Sci. U.S.A. 101:799-804.

Stephan, D., and Maiss, E. 2006. Biological properties of Beet mild yellowing virus derived from a full-length cDNA clone. J. Gen. Virol. 87:445-449.

Tatineni, S., Robertson, C. J., Garnsey, S. M., Bar-Joseph, M., Gowda, S., and Dawson, W. O. 2008. Three genes of Citrus tristeza virus are dispensable for infection and movement throughout some varieties of citrus trees. Virology 376:297-307.

Tatineni, S., Gowda, S., and Dawson, W. O. 2010. Heterologous minor coat proteins of Citrus tristeza virus strains affect encapsidation, but the coexpression of HSP70h and p61 restores encapsidation to wild-type levels. Virology 402:262-270.

Vancanneyt, G., Schmidt, R., Oconnorsanchez, A., Willmitzer, L., and Rochasosa M. 1990. Construction of an intron-containing marker gene Splicing of the intron in transgenic plants and its use in monitoring early events in Agrobacterium-mediated plant transformation. Mol. Gen. Genetics 220:245-250.

Vela, C., Cambra, M., Cortés, E., Moreno, P., Miguet, J. G., Pérez de San Román, C., and Sanz, A. 1986. Production and characterization of monoclonal antibodies specific for Citrus tristeza virus and their use for diagnosis. J. Gen. Virol. 67:91-96.

Vives, M. C., Martín, S., Ambrós, S., Renovell, A., Navarro, L., Pina, J. A., Moreno, P., and Guerri, J. 2008. Development of a full-genome cDNA clone of Citrus leaf blotch virus and infection of citrus plants. Mol. Plant Pathol. 9:787-797.

Voinnet, O., Rivas, S., Mestre, P., and Baulcombe, D. 2003. An enhanced transient expression system in plants based on suppression of gene silencing by the 19 protein of Tomato bushy stunt virus. Plant J. 33:949-956.

Wang, J., Turina, M., Stewart, L. R., Lindbo, J. A., and Falk, B. W. 2009. Agroinoculation of the Crinivirus, Lettuce infectious yellows virus, for systemic plant infection. Virology 392:131-136.

Yang, S. J., Carter, S. A., Cole, A. B., Cheng, N. H., and Nelson, R. S. 2004. A natural variant of a host RNA-dependent RNA polymerase is associated with increased susceptibility to viruses by Nicotiana benthamiana. Proc. Natl. Acad. Sci. U.S.A. 101:6297-6302. 